\title{
Autonomic Nervous System Response to Psychosocial Stress in Anorexia Nervosa: A Cross-Sectional and Controlled Study
}

\begin{abstract}
Ileana Schmalbach ${ }^{1,2 *}$, Benedict Herhaus ${ }^{1}$, Sebastian Pässler ${ }^{3}$, Sarah Runst ${ }^{3}$, Hendrik Berth ${ }^{2}$, Silvia Wolff ${ }^{3}$, Bjarne Schmalbach ${ }^{1}$ and Katja Petrowski ${ }^{1,4}$
\end{abstract}

${ }^{1}$ Department of Medical Psychology and Medical Sociology, University Medical Center of the Johannes-Gutenberg University Mainz, Mainz, Germany, ${ }^{2}$ Division of Psychological and Social Medicine and Developmental Neurosciences, Research Group Applied Medical Psychology and Medical Sociology, Carl Gustav Carus Faculty of Medicine, Technische Universität Dresden, Dresden, Germany, ${ }^{3}$ Department of Psychotherapy and Psychosomatic Medicine, University Hospital Carl Gustav Carus Dresden, Dresden, Germany, ${ }^{4}$ Abteilung für Innere Medizin III, Universitätsklinikum Carl Gustav Carus an der Technischen Universität Dresden, Dresden, Germany

OPEN ACCESS

Edited by:

Jena Shaw Tronieri, University of Pennsylvania, United States

Reviewed by:

Xosé A. Vila,

University of Vigo, Spain

Marwan El Ghoch,

Beirut Arab University, Lebanon

*Correspondence:

lleana Schmalbach

isteffen@uni-mainz.de

Specialty section:

This article was submitted to

Eating Behavior,

a section of the journal

Frontiers in Psychology

Received: 05 January 2021 Accepted: 11 February 2021

Published: 17 March 2021

Citation:

Schmalbach I, Herhaus B, Pässler S,

Runst $S$, Berth $H$, Wolff $S$,

Schmalbach $B$ and Petrowski $K$

(2021) Autonomic Nervous System Response to Psychosocial Stress in Anorexia Nervosa: A Cross-Sectional and Controlled Study.

Front. Psychol. 12:649848.

doi: 10.3389/fpsyg.2021.649848
To foster understanding in the psychopathology of patients with anorexia nervosa $\left(P_{A N}\right)$ at the psychological and physiological level, standardized experimental studies on reliable biomarkers are needed, especially due to the lack of disorder-specific samples. To this end, the autonomic nervous system (ANS) response to a psychosocial stressor was investigated in $n=19 \mathrm{P}_{\mathrm{AN}}$ (BMl: $18.7 \pm 3.3 \mathrm{~kg} / \mathrm{m}^{2}$ ), age, and gender-matched to $n=19$ healthy controls ( $\mathrm{HC}$; BMl: $\left.24.23 \pm 3.0 \mathrm{~kg} / \mathrm{m}^{2}\right)$. For this purpose, heart rate $(\mathrm{HR})$ and heart rate variability (HRV) parameters were assessed in a cross-sectional study design under two experimental conditions: (1) rest and (2) stress (Trier Social Stress Test). In addition, psychological indicators of stress were assessed. An $2 \times 2 \times 8$ ANOVA demonstrated similar HR and HRV patterns (except LF-HRV) between $\mathrm{P}_{\text {AN }}$ and $\mathrm{HC}$ at rest. Under stress, $P_{\text {AN }}$ (vs. HC) demonstrated a blunted HR [condition*time*group: $F_{(2.91,104.98)}=9.326$, $\left.p=0.000, \eta^{2}=0.206\right]$ and an attenuated HRV response (reduced SNS/PNS reactivity). Significant effects of stress appraisal (SA) and BMI on HRV-reactivity were revealed. $\mathrm{SA}$ on SDNN $=$ Condition*time $* \mathrm{SA}=F_{(4.12,140.15)}=2.676, p=0.033, \eta^{2}=0.073$. $\mathrm{BMI}$ on LF/HF-Ratio $=$ Condition*time*BMI $=F_{(3.53,60.16)}=3.339, p=0.019, \eta^{2}=$ 0.164. Psychological indices suggested higher levels of chronic and appraised stress in $\mathrm{P}_{\mathrm{AN}}$ relative to $\mathrm{HC}$. Additional analyses demonstrated that ED-symptoms are highly correlated with the latter constructs, as well as with psychological burden, but not with weight. Further, it was shown that abnormalities in reactivity persisted despite normalized ANS activity. Overall, we suggested that besides weight recovery, improvement in stress appraisal could be beneficial for cardiac health. In this light, a combination of therapy (e.g., development and activation of coping skills, cognitive reappraisal) and biofeedback training may improve treatment outcomes and regulate stress reactivity.

Keywords: eating disorders, anorexia nervosa, trier social stress test, heart rate variability, laboratory stress induction, $\mathrm{HRV}$ in AN 


\section{INTRODUCTION}

Heart Rate Variability (HRV) is a convenient method to assess Autonomic Nervous System (ANS) functionality: It reflects the contribution of parasympathetic (PNS), and sympathetic (SNS) activity, and acts as a biomarker for health, and adaptive stress behavior in social contexts (Marques et al., 2010; Young and Benton, 2015; Shaffer and Ginsberg, 2017; Lischke et al., 2018). A balanced HRV is related to positive health outcomes, while a low to physical and psychological morbidity (Thayer et al., 2010; Young and Benton, 2018) as in the case of patients with anorexia nervosa $\left(\mathrm{P}_{\mathrm{AN}}\right)$. Anorexia nervosa $(\mathrm{AN})$ is an eating disorder (ED), typically characterized by an exaggerated fear of weight gain, constant weight and shape concerns in spite of being underweight (BMI $<17.5 \mathrm{~kg} / \mathrm{m}^{2}$; (DSM-5, 2013; Seidel et al., 2018)). $P_{\text {AN }}$ face several medical risks and exhibit a wide range of ANS dysfunctions (e.g., cardiovascular irregularities), registering at least five times greater rate of death than in the general population (Katzman, 2005; Arcelus et al., 2011; Keshaviah et al., 2014; Sachs et al., 2016). Treatment outcomes are poor (Harbottle et al., 2008; Watson and Bulik, 2013; Murray et al., 2019) and many patients still report decreased well-being and low quality of life (Jenkins et al., 2011; Tomba et al., 2017). Thus, innovative treatments are urgently needed. The role of psychosocial stress (e.g., social evaluation, exclusion, contexts related to performance; Kirschbaum et al., 1993; Pruessner et al., 2003; Dickerson and Kemeny, 2004) in the onset and maintenance of AN, as well as its effects on the ANS functionality has been frequently thematized (Caglar-Nazali et al., 2014; Monteleone et al., 2018; Wierenga et al., 2018; Young and Benton, 2018). Almost $90 \%$ of $\mathrm{P}_{\mathrm{AN}}$ exhibit cardiac abnormalities (Giovinazzo et al., 2019) with a high incidence of bradycardia (i.e., low resting HR <50/min; Mazurak et al., 2011; Portilla, 2011; Gibson et al., 2020). However, experimental studies on their ANS response are underrepresented, especially in the context of psychosocial stress. Additionally, empirical evidence on ANS reactivity is still inconsistent. In terms of HRV tone (at rest), three different patterns are reported in $\mathrm{P}_{\mathrm{AN}}$ : some studies found increased parameters (Roche et al., 2004; Bär et al., 2006), while others decreased (Platisa et al., 2006; Lachish et al., 2009), and a third group of papers unveiled comparable results between patients and healthy controls (HC; Murialdo et al., 2007; Vigo et al., 2008). Nevertheless, a general PNS/SNS imbalance with a trend in parasympathetic hyperactivity (Mazurak et al., 2011; Jacoangeli et al., 2013; Bomba et al., 2014) and sympathetic hypoactivity (at rest; Mazurak et al., 2011) has been constantly observed in $\mathrm{P}_{\mathrm{AN}}$. Concerning heart rate (HR) reactivity, some researchers observed a blunted response in patients (Monteleone et al., 2011, 2018; Het et al., 2015, 2020) compared to healthy individuals, while others found a comparable reactivity between both groups (Vocks et al., 2008; Het et al., 2020). Regarding the cardiovascular reactivity as indexed by HRV, patients demonstrated a pronounced PNS reactivity (lower HR + stronger HF-HRV) and a SNShyporeactivity as indexed by salivary Alpha-Amylase (sAA; Het et al., 2015, 2020). Although, the latter was not supported by LF-HRV, since it was comparable in patients and controls (Het et al., 2015). Still, HRV analyses were not specific to $\mathrm{P}_{\mathrm{AN}}$, but to an ED-mixed sample. Indeed, when studying a disorderspecific sample of $\mathrm{P}_{\mathrm{AN}}$, Rommel et al. (2015) demonstrated an attenuated parasympathetic response after stress induction (via 80 s. film). Other HRV parameters, rather than a low HF-HRV were not reported, leaving the role of the SNS unknown. These inconsistencies can be explained by differences in methodological procedures (e.g., unstandardized stressors), whereby the degree of ANS activation is not clear. Other influential factors are the diverse methods to analyze (e.g., WT, wavelet transformation; Rommel et al., 2015) and report ANS-parameters (e.g., sAA, either LF-HRV, or HF-HRV values) providing either a reliable nor a full picture of the ANS functionality (Bosch et al., 2011). Further, heterogeneity in patient population (e.g., mixed EDgroups) limits the comparability of results and small sample sizes make findings susceptible to random effects. Researches recommended to investigate these results in the light of EDspecific samples (Vocks et al., 2008; Het et al., 2020) due to differences in their stress response (Monteleone et al., 2011; Peschel et al., 2016). From this perspective, there is a need to clarify the ANS response in $\mathrm{P}_{\mathrm{AN}}$. In general, experimental evidence on the ANS reactivity to psychosocial stress in $\mathrm{P}_{\mathrm{AN}}$ is scarce and ambiguous. Considering this background, the purpose of the present study is to expand $\mathrm{P}_{\mathrm{AN}}$-specific data and examine HRV parameters (see Table 1) under controlled conditions. To this end, we implemented a psychosocial and a standardized stressor (i.e., Trier Social Stress Test -TSST; Kirschbaum et al., 1993).

\section{Hypotheses}

$\left(\mathbf{H}_{1}\right)$ Since bradycardia is highly prevalent in $\mathrm{P}_{\mathrm{AN}}$ (Mazurak et al., 2011; Gibson et al., 2020), we estimated a significantly lower baseline HR in $\mathrm{P}_{\mathrm{AN}}$ than in HC. $\left(\mathbf{H}_{2}\right)$ We hypothesized PNS hyperactivity and a decreased SNS in $\mathrm{P}_{\mathrm{AN}}$ at rest, when compared to HC (Mazurak et al., 2011; Jacoangeli et al., 2013; Bomba et al., 2014). $\left(\mathbf{H}_{3}\right)$ We expected a blunted HR response to the TSST as consistently evidenced (Monteleone et al., 2011, 2018; Het et al., 2015, Het et al., 2020). ( $\left.\mathbf{H}_{4}\right)$ In consonance with studies based on the TSST (Het et al., 2015, 2020), we assumed differences in ANS reactivity between both groups, whereby $\mathrm{P}_{\mathrm{AN}}$ expressed a low HRV reactivity with a $\left(\mathbf{H}_{5}\right)$ reduced SNS and pronounced PNS-reactivity.

\section{METHOD \\ Participants}

In the present study $n=19 \mathrm{P}_{\mathrm{AN}}$ (BMI: $18.70 \pm 3.30 \mathrm{~kg} / \mathrm{m}^{2}$ ) and $n=19 \mathrm{HC}$ (BMI: $24.23 \pm 3.04 \mathrm{~kg} / \mathrm{m}^{2}$ ) were recruited to investigate the effects of stress on the ANS. In general, participants between 18 and 65 years of age were eligible. Patients with a primary diagnosis of AN were eligible and recruited at the Polyclinic for Psychotherapy and Psychosomatic in Dresden, Germany. Patients were diagnosed with AN prior admission to an inpatient treatment and were enrolled in the study after a stabilization period, since some were artificially nourished. Consequently, some patients experienced weight restoration. Before participation, $\mathrm{P}_{\mathrm{AN}}$ were re-screening based on the Structured Clinical Interview (SCID) of the Diagnostic 
TABLE 1 | Metrics of heart rate variability.

The power spectrum analysis of the HRV evaluates the quantitative contribution of time (RMSSD = Square root of the mean squared differences of successive NN interval; SDNN, Standard deviation normal to normal) and frequency domains (HF, high frequent and LF, low frequent LF) to the total variance (power) of heart rate (HR).

- RMSSD includes sympathetic influences and is associated to HF power, but is tendentially moderated by the PNS than SDNN (Shaffer and Ginsberg, 2017).

- SDNN indicates a general HRV modulated by PNS and SNS branches. Mazurak et al. (2011) added, that it also records endocrine and thermoregulatory processes.

- HF is a marker of the parasympathetic vagal tone being respiration dependent (Force, 1996; Stein and Kleiger, 1999; Shaffer and Ginsberg, 2017).

- LF signals activity in both systems: PNS and SNS (Cohen et al., 2000; Shaffer and Ginsberg, 2017).

- The LF/HF-ratio represents the balance between PNS and SNS activity. According to this model, a low LF/HF ratio stands for PNS dominance while a high ratio reflects SNS overactivation (Mazurak et al., 2011; Shaffer and Ginsberg, 2017). However, the SNS contribution to LF power varies depending on the testing context: e.g., under resting conditions, it shows PNS and baroreflex, rather than SNS activity (Kemper et al., 2007; Goldstein et al., 2011).

and Statistical Manual of Mental Disorders (DSM-IV; First et al., 1997; Wittchen et al., 1997). P AN with other mental disorders besides depression (e.g., post-traumatic-stress disorder, borderline personality disorder, schizophrenia), chronic illness, and medication treatment were excluded. HC were recruited through online media, newspapers, and bulletin boards at different universities, and were screened for mental or physical conditions. Only mentally and physically healthy participants were included. HC with an abnormal BMI, chronic illness, medication treatment, and stressful life events in the past 6 months were excluded. Participants who did not refrain from eating or smoking $3 \mathrm{~h}$ before testing were excluded too. Six participants were excluded due to substantial missing data resulting in a final sample of $N=38$.

Every participant received an expense allowance of 50 Euro after participation on two test days-within a week. A description of all $N=38$ participants is displayed in Table 2. Ethical approval was obtained from the Ethics Committee of the Medical faculty of the Technical University of Dresden, Germany (No\#EK25012013).

\section{Procedure}

$\mathrm{P}_{\mathrm{AN}}$ and $\mathrm{HC}$ were scheduled on 2 days for two different experimental conditions (stress and rest) in order to minimize the probability of errors. All participants were registered between 2:00 p.m. and 4:00 p.m. and were previously requested to refrain from eating, drinking and smoking prior examination. Upon arrival, participants signed an informed consent form and filled out psychological measures for $\sim 30 \mathrm{~min}$. Thereafter, they were fitted with a long-term electrocardiogram (ECG) belt-recorder for continuous ECG recording (SysVital, Fraunhofer IPMS, Germany). The participants were randomly assigned either to the stress or to the resting condition: 19 participants started with the resting, while the other 19 with the stress condition. The derived HR and HRV parameters were computed over 3-min intervals during a pre-TSST resting period ( $15 \mathrm{~min})$, during stress exposure (15 min TSST), and during a post-TSST recovery period (40 min). These data were collected over eight Measurement timepoints = 1 (Baseline), 2 (Preparation), 3 (Before public speaking), 4 (After a math task), 5-8 (Recovery Phase). The measurements in the control condition were collected on equivalent timepoints (see Figure 1). The testing started with the resting period ( $15 \mathrm{~min}$.) and was concluded with a recovery period lasting $40 \mathrm{~min}$. In the next testing day, the participants took part on the remaining condition. During the respective experimental condition every participant completed the Primary Appraisal Secondary Appraisal questionnaire (PASA; Gaab et al., 2005). At the end of the resting or stress condition, the participants rated their perceived stress by means of the visual analog scale (VAS; Flint et al., 2000). An overview of the procedure is illustrated in Figure $\mathbf{1 .}$

\section{Experimental Conditions: Stress vs. Rest Stress Condition}

The Trier Social Stress Test (TSST; Kirschbaum et al., 1993; Kudielka et al., 2007) is a validated and a standardized procedure, which is world-wide recognized for its effective stress induction and activation of the ANS (Kirschbaum et al., 1993; Mohammadi et al., 2019). In short, it consists in a social evaluation with a lack of feedback, in front of a selected two-person panel and a mental arithmetic test, divided in three phases lasting 5 min each (1st: Speech preparation. 2nd: Public speaking. 3rd: Arithmetic task).

\section{Resting Condition}

In this experimental phase participants could read fordable literature in a quiet and secluded room.

\section{Heart Rate and Heart Rate Variability}

The HR and HRV variables were computed by means of a three-channel ECG. The recordings were taken from all of the participants during the entire experimental conditions. A heart rate tachogram was determined from the ECG data by specifying the heart beats and evaluating the RR intervals. Subsequently, the ECG recordings were sampled with a frequency of $250 \mathrm{~Hz}$, an amplitude quantification of $12 \mathrm{bit}$, and an analogous recording bandwidth with $0.5-80 \mathrm{~Hz}$. Next, the heart beat spotting was computed by means of a wavelet min-max-pair based automated QRS detector (Zaunseder et al., 2008). Prior to analyses, data was filtered for artifacts and erroneous R-R interval by the Polar ProTrainer 5 (Polar, Germany). This software works with an automatic filtering method (filter power: moderate, minimum protection zone: $6 \mathrm{sqm}$ ). In the present study, the HRV parameters were calculated in three min. intervals. The following time (expressed in $\mathrm{ms}$ ) and frequency $\left(\mathrm{ms}^{2}\right)$ parameters were analyzed to specify $H R V=H F, L F$ power, $L F / H F$ ratio, RMSSD, and SDNN. 
TABLE 2 | Characteristic of the participants - Demographic variables.

\begin{tabular}{|c|c|c|c|c|}
\hline & $\mathbf{P}_{\mathrm{AN}}$ & $\mathrm{HC}$ & $t / U$ & $p$ \\
\hline Total $(N)$ & 19 & 19 & & \\
\hline Female, $n(\%)$ & 17 (89.5) & 17 (89.5) & & \\
\hline Age $M(S D)$ & $26.05(5.49)$ & $24.21(5.54)$ & 1.03 & 0.31 \\
\hline BMI M (SD) & $18.70(3.30)$ & $24.23(3.04)$ & -5.36 & $0.000^{\star \star \star}$ \\
\hline Contraceptives $n$ (\% females) & $44.73(17)$ & $31.57(12)$ & 3.64 & 0.062 \\
\hline Sport (MR) & 16.50 & 22.50 & $43.50^{(a)}$ & 0.961 \\
\hline Sleep problems (MR) & 24 & 15 & $42.00^{(a)}$ & 0.849 \\
\hline
\end{tabular}

$P_{A N}$, Participants with Anorexia nervosa; HC, Healthy Controls; M, Mean; MR, MeanRank; SD, Standard Deviation; TICS, Trier Inventory Chronic Stress; $<p \leq 0.001^{\star \star *}$, (a) Mann-Whitney-Test.

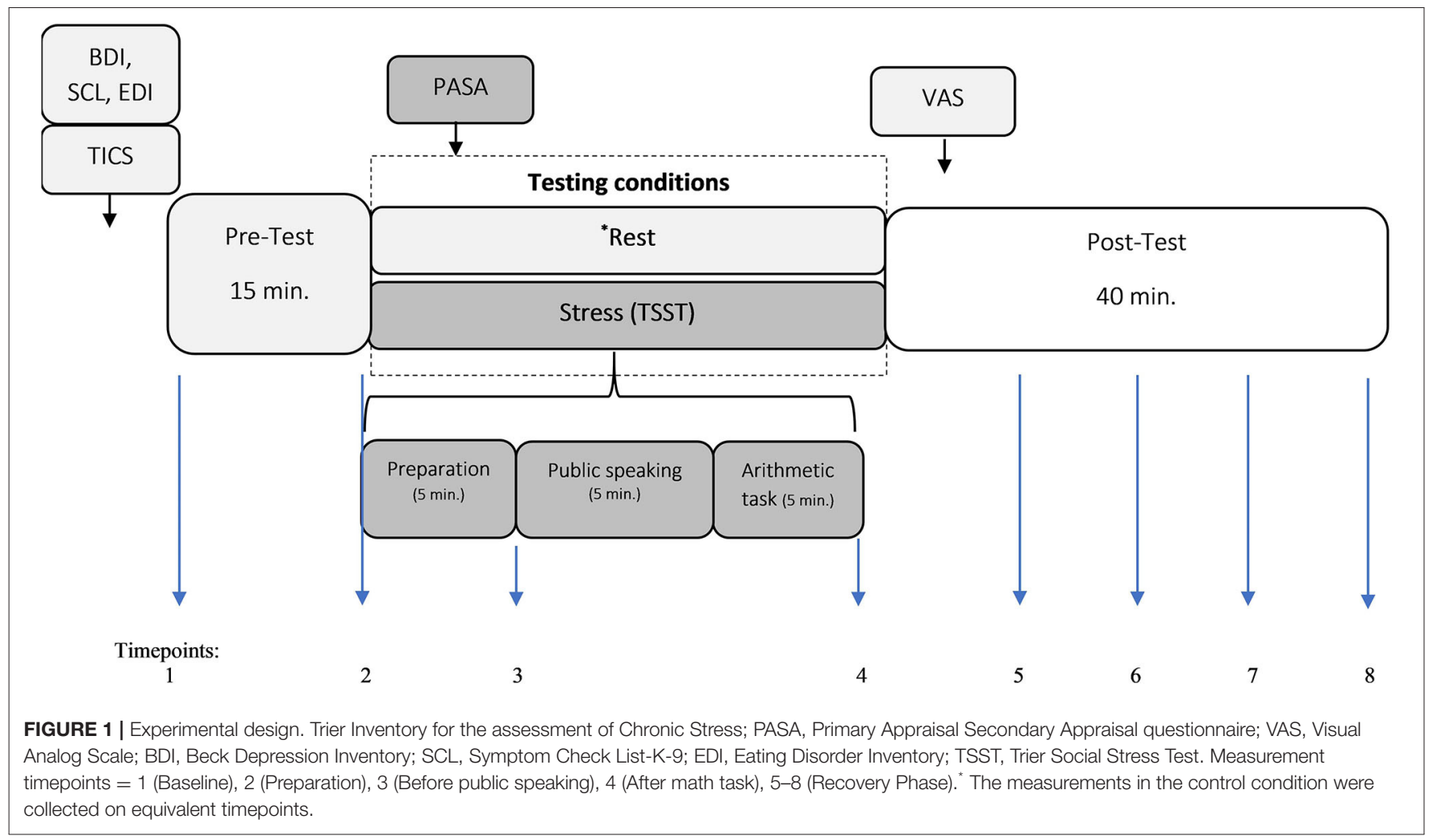

\section{Psychological Questionnaires}

Trier Inventory for the assessment of Chronic Stress (TICS-9; Schulz et al., 2004; Petrowski et al., 2019a). The TICS-9 is a short version of the original 57-item TICS. We applied the short form to assess chronic stress during the last 3 months. This version includes nine items reflecting all dimensions of the long version (e.g., work and social overload, pressure to perform, social tensions). The items can be rated from 0 to 5 (0 $=$ never, $1=$ rarely, $2=$ sometimes, $3=$ often, $4=$ very often). Higher values suggest greater stress. Satisfactory psychometrics have been evidenced in several studies, with Cronbach's Alpha ranging from $\alpha=0.88-0.91$ (Petrowski et al., 2012, 2018, 2019a).
Primary Appraisal Secondary Appraisal questionnaire (PASA; Gaab et al., 2005). This scale evaluates situational and disorderspecific cognitions. The primary appraisal evaluates specific situations as threatening or challenging. The second appraisal reflects perceived coping capabilities (self-concept and control expectancy). Based on these subscales, a total stress index (SI) can be calculated. It comprises 16 items using a 6-point Likert scale $(1=$ completely disagree to $6=$ completely agree $)$ and exhibits reasonable psychometric properties (Cronbach's alpha $=$ 0.61-0.83; Gaab et al., 2005; Carpenter, 2016).

Visual Analog Scale (VAS; Flint et al., 2000). The VAS is a widespread scale, due to its economy and reliability to evaluate stress. With this tool, our participants rated their subjective 
TABLE 3 | Psychological variables and HRV-Reactivity in Patients with Anorexia Nervosa.

\begin{tabular}{|c|c|c|c|c|c|c|}
\hline$P_{\text {AN }}$ & Present scores $M(S D)$ & \multicolumn{3}{|c|}{ Norm values } & \multicolumn{2}{|c|}{ Interpretation } \\
\hline $\mathrm{BDI}$ & $42.46(27.39)$ & \multicolumn{3}{|c|}{$\begin{array}{c}<14=\text { normal } \\
14-19=\text { mild } \\
20-28=\text { moderate } \\
29-63=\text { severe depression }\end{array}$} & \multicolumn{2}{|c|}{ Severe depression } \\
\hline SCL (GSI) & $12.57(8.13)$ & \multicolumn{3}{|c|}{ Score $12={ }^{*}$ Percentile 93\% } & \multicolumn{2}{|c|}{ Pronounced psychological burden } \\
\hline EDI & $148.94(61.47)$ & \multicolumn{3}{|c|}{ Score $140-155={ }^{*}$ Percentile $=85 \%$} & \multicolumn{2}{|c|}{ Pronounced ED-symptoms } \\
\hline $\begin{array}{l}P_{\mathrm{AN}} \leq 17.5 \text { vs. } P_{\mathrm{AN}} \geq \\
17.5 \mathrm{BMI}\left(\mathrm{Kg} / \mathrm{m}^{2}\right)\end{array}$ & (a) $U$ & $z$ & $p$ & $\eta^{2}$ & & \\
\hline $\mathrm{BDI}$ & 28.50 & -0.906 & 0.365 & 0.121 & & \\
\hline SCL (GSI) & 39.00 & -0.414 & 0.679 & 0.032 & & \\
\hline EDI & 38.50 & -0.454 & 0.650 & 0.031 & & \\
\hline TICS & 41.00 & -0.248 & 0.840 & 0.023 & & \\
\hline PASA-SI & 43.49 & -0.040 & 0.970 & 0.017 & & \\
\hline VAS-TSST & 43.50 & -0.041 & 0.967 & 0.011 & & \\
\hline \multirow[t]{2}{*}{ HRV-reactivity } & \multicolumn{3}{|c|}{ Condition*time*group } & & \multicolumn{2}{|c|}{ Group } \\
\hline & $F(d f)$ & $p$ & $\eta^{2}$ & $F(d f)$ & $p$ & $\eta^{2}$ \\
\hline $\mathrm{HR}$ & $0.670(3.85,65)$ & 0.611 & 0.038 & $0.193(1,17)$ & 0.666 & 0.011 \\
\hline SDNN & $1.69(2.11,36.01)$ & 0.196 & 0.091 & $0.079(1,17)$ & 0.781 & 0.005 \\
\hline RMSSD & 230 (2.03., 34.64) & 0.790 & 0.013 & $1.98(1,17)$ & 0.177 & 0.104 \\
\hline $\mathrm{HF}$ & $0.140(2.57,36.09)$ & 0.87 & 0.009 & $0.98(1,17)$ & 0.333 & 0.055 \\
\hline LF & $0.730(2.28,32.57)$ & 0.484 & 0.041 & $0.073(1,17)$ & 0.790 & 0.004 \\
\hline LF/HF & $0.158(1.69,28.76)$ & 0.85 & 0.009 & $0.194(1,17)$ & 0.669 & 0.011 \\
\hline
\end{tabular}

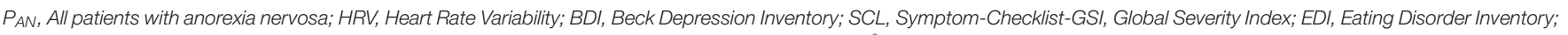
TICS, Trier Inventory Chronic Stress; PASA-SI, Primary Appraisal Secondary Appraisal - Stress Index. ${ }^{*} P_{\text {AN }}$ Scored higher than $80 / 90 \%$ of the norm group. (a) Mann-Whitney-Test.

perception of stress in each experimental condition. Values ranged between no stress to severe stress (0-100; Lesage et al., 2012).

Symptom-Check-List-9 (SCL-K-9; Klaghofer and Brähler, 2001). This scale is a short version of the original SymptomChecklist-90-Revised (Franke and Derogatis, 2002) which evaluates general psychopathology (e.g., somatic symptoms, interpersonal sensitivity, anxiety). It also provides a global severity index (GSI) as an indicator of overall psychological distress; whereby higher scores indicate higher levels of psychopathological distress and greater symptom severity. For the purpose of the present study, we only reported GSI-values. The items can be rated on a 5 -point Likert scale $(0=$ never to $4=$ very often). The sum score is calculated by addition of all item scores. The scale demonstrates satisfactory psychometric properties ( $\alpha=0.83-0.87$; Klaghofer and Brähler, 2001; Prinz et al., 2013; Sereda and Dembitskyi, 2016; Petrowski et al., 2019b). Normative percentile values specific to age and gender are reported by (Petrowski et al., 2019b).

Beck Depression Inventory (BDI; Beck et al., 1961; Hautzinger et al., 1994). The BDI is a self-report questionnaire with 21 items that can be rated from 0 to $3(0-63)$. The total score is calculated by addition of the items. Higher scores indicate greater symptom severity. Cut-off values are established as follow: $<14=$ normal, 14-19 = mild depression, 20-28 = moderate depression, 29-63 $=$ severe depression. Its psychometric properties are satisfactory ( $\alpha=$ 0.89-0.94.; Beck et al., 1996; Kühner et al., 2007).
Eating Disorder Inventory (EDI; Garner et al., 1983; Thiel and Paul, 1988). The EDI measures symptoms and attitudes relevant to pathological eating behavior in 64 items comprised in 8 dimensions (e.g., Drive for Thinness, Body Dissatisfaction, Interpersonal Distrust). The items are evaluated on a 6-point rating scale $(0=$ never to $5=$ always). The psychometric properties are satisfactory $(\alpha=0.72-0.92$; Thiel and Paul, 1988; Dinkel et al., 2005). In the present study, the evaluation of the EDI-score was based on the EDI-scores provided by (Kappel et al., 2012).

\section{Statistical Analyses}

All statistical analyses were performed with the Statistical Package for the Social Sciences (SPSS version 24.0). The sphericity hypothesis was verified using the Mauchly test and Greenhouse-Geisser adjusted $p$-values are reported when necessary. The optimum statistical sample size was calculated with the $G^{*}$ power program (version: 3.1.9.2.). Based on a medium effect size of Cohen's $f=0.25$, two groups $\left(\mathrm{P}_{\mathrm{AN}}\right.$ and $\mathrm{HC}), n=8$ repetitions, a significant level of $p=0.05$, power of $80 \%(1-\beta=0.80)$, and after Bonferroni-correction, a total sample size of $n=19$ for within-subjects factor and $n=$ 38 for between-subjects factor was needed. Mean differences between $\mathrm{P}_{\mathrm{AN}}$ and $\mathrm{HC}$ in demographic characteristics (e.g., sport activity, cigarette smoking) and psychological measures, were specified by independent $t$-tests and non-parametric tests (i.e., Mann-Whitney). A two-way ANOVA for repeated 
measures with the between-factor group ( $\mathrm{P}_{\mathrm{AN}}$ vs. $\mathrm{HC}$ ) and the within-factor for condition (rest vs. stress) and time (8 $x$ ) was performed to calculate main or interaction effects in the parameters of interest $(\mathrm{HR}, \mathrm{HRV})$ in response to the experimental interventions. Additional $t$-tests were performed to specify time-independent differences between the experimental groups in HR and HRV parameters.

Additional analyses. Since the main topic of the present study refers to ANS reactivity to a psychosocial stressor, the psychological features of the participants play a role and could provide insights in this regard. Since weight is a main concern in $\mathrm{P}_{\mathrm{AN}}$, this variable was considered too. Therefore, the following additional analyses were conducted. The effects of BMI, ED-symptomatology (EDI), psychological burden (BDI, GSI), chronic (TICS) and appraised stress (PASA-SI) on the HR and HRV response were estimated by means of a two-way ANCOVA for repeated measures $2 \times$ $2 \times 8$. Subsequently, post-hoc-tests (i.e., estimated marginal means and bonferroni adjusted pairwise comparisons) were computed to specify differences throughout the measurement timepoints of relevant parameters. Discrepancies in subjective stress appraisal (PASA-SI) before and after stress exposure were calculated with ANOVAs for repeated measures. Differences in other psychological scales were analyzed by $t$-tests. PearsonProduct-Moment correlations were computed to determine the relationship between chronic stress (TICS), stress appraisal (PASA), BMI, and psychological burden (i.e., GSI, BDI, EDI) in our sample of $\mathrm{P}_{\mathrm{AN}}$. The significance level was defined'as $p<0.05$.

\section{RESULTS}

\section{Psychological Measures}

A summary of the sociodemographic variables of all study participants is displayed in Table 2. $\mathrm{P}_{\mathrm{AN}}$ and $\mathrm{HC}$ were successfully matched for age and gender. Significant differences between the groups were identified in: BMI, sleeping problems and chronic stress. Additionally, $\mathrm{P}_{\mathrm{AN}}$ showed highly pronounced values in psychological distress (GSI), depression (BDI) and ED symptomatology (EDI; Table 3). Since some of the $\mathrm{P}_{\mathrm{AN}}$ had recovered some weight $\left(\mathrm{BMI}=17.5-18.7 \mathrm{Kg} / \mathrm{m}^{2}\right)$, while others were still underweight $\left(\mathrm{BMI}<17.5 \mathrm{Kg} / \mathrm{m}^{2}\right)$ we re-analyzed data comparing the two groups in terms of psychological measures, HR and HRV parameters. The analyses indicated comparable results (Table 3 ).

\section{Stress Perception und Appraisal}

Acute stress perception (VAS) was comparable in both groups $\left[F_{(1,36)}=2.95, p<0.094, \eta^{2}=0.07\right]$, expressing significantly higher values after stress exposure, which indicated a successful stress induction $\left[F_{(1,36)}=93.03, p<0.000, \eta^{2}=0.72\right]$. In contrast, stress appraisal (PASA-SI) was sig. higher in $\mathrm{P}_{\mathrm{AN}}$ than in $\mathrm{HC}\left[F_{(1,34)}=13.22, p<0.001, \eta^{2}=0.28\right]$. PASA-subscales indicated differences in: Threat $\left[t_{(36)}=2.166, p=0.037\right]$, SelfConcept $\left.t_{(36)}=-3.625, p=0.001\right)$, and Secondary Appraisal $\left(t_{(36)}\right.$ $=-3.171 ; p=0.003)$.

Chronic and appraised stress were correlated with psychological variables. PASA-SI and EDI $r(19)=0.500, p$ $=0.040$, but not between PASA-SI and BMI, BDI, or GSI. TICS

TABLE 4 | HRV Parameters in $\mathrm{P}_{\mathrm{AN}}$ and HC - ANOVA results.

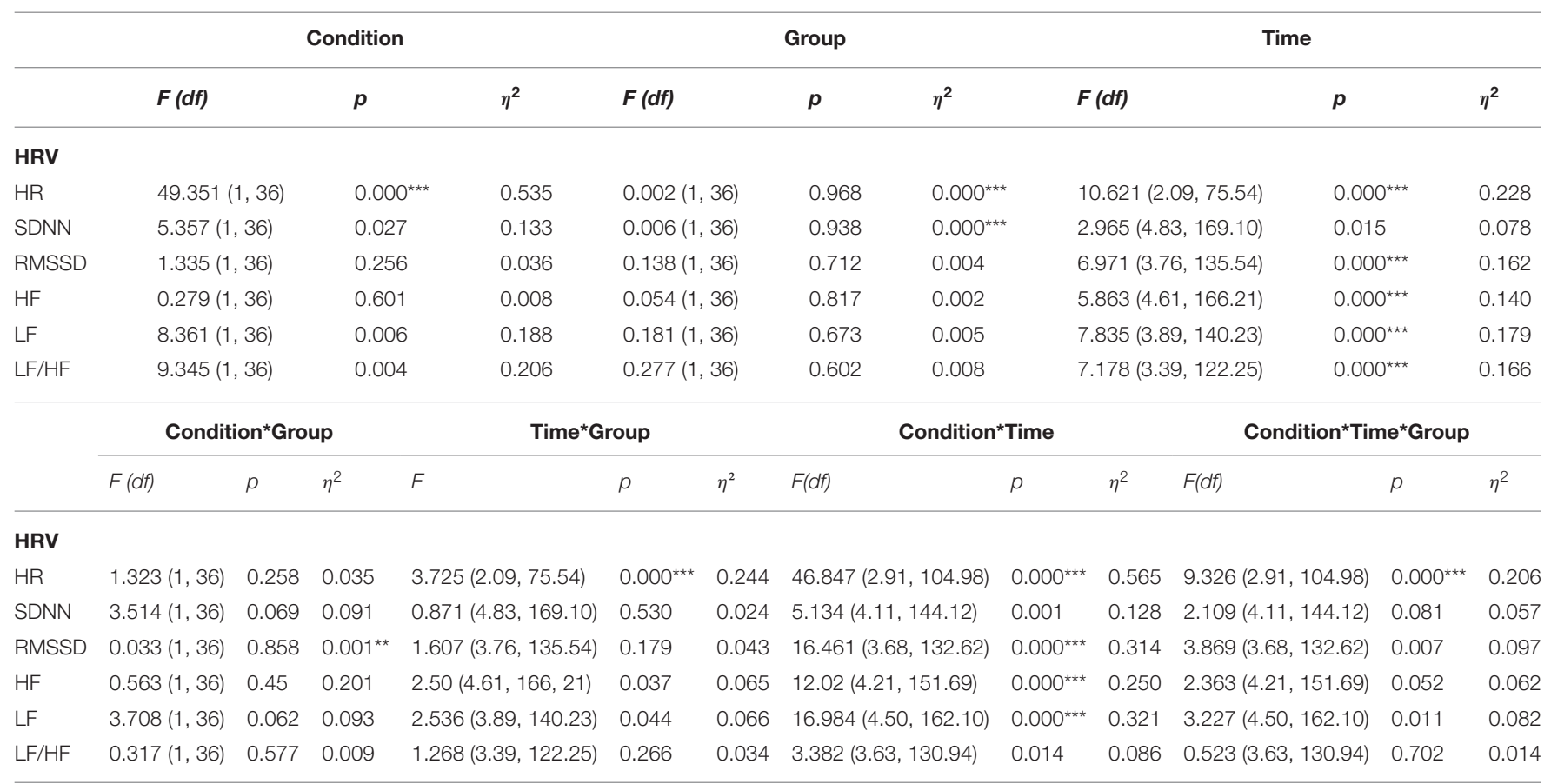

$P_{A N}$, Participants with Anorexia Nervosa; HC, Healthy Controls; M, Mean; SD, Standard Deviation; HRV, Heart Rate Variability. HR, Heart Rate; SDNN, standard deviation of NN intervals. RMSSD, Root mean square successive differences, $H F$, high frequency; $L F$, low frequency; $L F / H F$, Low frequency/ high frequency ratio, $p \leq 0.05^{*} ; p \leq 0.01^{* *} ; p \leq 0.001^{* * *}$. 
and BDI, $r(19)=0.540, p=0.021$, GSI $r(19)=0.722, p=0.000$, EDI $r(19)=0.644, p=0.003$, but not between TICS and BMI.

\section{Psychological Symptoms and Stress on the ANS Response}

The effects of the ED-symptoms, psychological burden (BDI, GSI), appraised (PASA-SI), and chronic stress (TICS) on the HR and HRV response were estimated for each HRV-parameter by means of a two-way ANCOVA for repeated measures. Only stress appraisal and BMI affected ANS-reactivity. Significant effects were found in two parameters: SDNN; LF/HF-Ratio. Perceived stress on SDNN = Condition*time*PASA-SI $F_{(4.12,140.15)}=$ 2.676, $p=0.033, \eta^{2}=0.073$. Further analyses suggested that SDNN-HRV was distinctively low during stress and high at rest in individuals with a less pronounced stress appraisal (HC), this variability was less visible in participants with a higher stress appraisal $\left(\mathrm{P}_{\mathrm{AN}}\right)$. BMI on LF/HF-Ratio $=$ Condition*time*BMI $=F_{(3.53,60.16)}=3.339, p=0.019, \eta^{2}=0.164$. Additional analyses indicated that participants with a normal BMI $\left(21-25 \mathrm{~kg} / \mathrm{m}^{2}\right)$, in this case $\mathrm{HC}$, clearly displayed a higher ratio during stress and a lower during rest. This pattern becomes less pronounced at a lower BMI, exhibiting an overall reduced ratio $\left(\mathrm{P}_{\mathrm{AN}}\right)$. Overall, no further sig. effects were shown $\left(F s<1, p=0.080, \eta^{2}=0.110\right)$.

\section{HRV Parameters}

All HRV-data were tested for normal distribution with Kolmogorov-Smirnov test (K-S test). All HRV-parameters illustrated a skewed distribution (except for HR and SDNN) and were log-transformed for subsequent statistical analyses. The values and analyses of HR and HRV derived parameters are displayed in Tables 4, 5a,b.

$\left(\mathbf{H}_{1}\right)$. HR values (at rest) were comparable between $\mathrm{P}_{\mathrm{AN}}$ and HC (Tables $4, \mathbf{5 a}, \mathbf{b}) .\left(\mathbf{H}_{2}\right)$. In terms of HRV tone, a significance was shown in LF-with $\mathrm{P}_{\mathrm{AN}}$ showing lower values than controls (Tables $\mathbf{4}, \mathbf{5 a}, \mathbf{b}$ ). The remaining parameters were comparable between groups, PNS hyperactivity was not observed in $\mathrm{P}_{\mathrm{AN}}$ at rest (Tables 4, 5a,b). $\left(\mathbf{H}_{3}\right)$. Only a sig. effect of condition*time*group was shown. $\mathrm{P}_{\mathrm{AN}}$ clearly illustrated a blunted $\mathrm{HR}$ response in comparison to the HC (see Tables 4, 5a,b; Figure 2). $\left(\mathbf{H}_{4}\right)$. In terms of group differences in ANS reactivity, the following patterns were revealed: SDNN. Only a significant effect of time and condition and an interaction effect: condition*time were shown, indicating increased values during stress than at rest in all participants over time (Tables 4, 5a,b; Figure 3). At a descriptive level, a weaker reactivity was visible in $\mathrm{P}_{\mathrm{AN}}$ relative to the $\mathrm{HC}$ (see Table 5b). RMSSD. A significant effect of time and two sig. interaction effects were observed: (1) Condition*time (2) Condition*time* group. $\mathrm{P}_{\mathrm{AN}}$ showed an attenuated stress response compared to the HC. No further sig. effects were demonstrated (Tables 4, 5a,b; Figure 4). HF. A sig. effect of time and two sig. interaction effects were found: (1) Condition*time and (2) Time* group. Overall, there were sig. differences in HF-values, with $\mathrm{P}_{\mathrm{AN}}$ recording higher values than HC over time. The interaction effect of condition*time* group was not significant (Tables 4, 5a,b, Figure 5). LF. A sig. effect of condition and time and a multiple sig. interaction effects were evinced: (1) Time*group, (2) condition*time, (3) condition*time* group, indicating a lower HRV-LF-reactivity in patients, compared to HC (Tables 4, 5a,b, Figure 6). LF/HFRatio. Only a highly sig. effect of condition and time and a sig. interaction effect of condition*time were revealed: All participants displayed a higher ratio over time during stress than at rest (Tables $\mathbf{4}, \mathbf{5 a}, \mathbf{b}$, Figure 7 ). $\left(\mathbf{H}_{5}\right)$. In terms of HRV reactivity, $\mathrm{P}_{\mathrm{AN}}$ exhibited a reduced SNS reactivity, without PNS dominance (see Tables 4, 5a,b). Overall, large to medium effect sizes were revealed (see Table 4).

\section{DISCUSSION}

Measuring HRV as a proxy to assess ANS reactivity has many advantages and allows a detailed analysis of the SNS and PNS contribution. In addition, HRV reflects the capacity of the body to deal with stress and predicts psychological and physiological health. Investigating the HRV activity and its alterations might aid the development of novel ways to target AN-symptomatology and reduce mortality rates. For this purpose, we extensively investigated the ANS reactivity to a psychosocial stressor in $\mathrm{P}_{\mathrm{AN}}$ and a matched sample of HC under highly standardized laboratory conditions and analyzed different HRV-parameters. In sum, the stress induction was successful (VAS). Compared to HC, PAN appraised (PASA) the experimental procedures as more threatening and experienced themselves as less influential over the ongoing circumstances. Further, they felt less capable of coping with the given situation than healthy adults. Moreover, chronic and appraised stress were more strongly associated with psychological symptoms than with weight. Concerning reactivity, stress appraisal and weight significantly affected the ANS response (i.e., SDNN; LF/HF-Ratio) with $\mathrm{P}_{\mathrm{AN}}$ showing a reduced ratio overall, relative to the HC. In this regard, underweight and weight recovered patients were comparable in terms of cardiovascular reactivity and psychological measures. Their BMI variations were not big enough to differently affect reactivity.

Concerning HR and HRV, our data revealed similarities between the groups in almost all parameters during resting conditions. A significant difference was only shown in LFHRV, indicating a decreased baroreflex activity in patients, compared to controls. In terms of HRV-reactivity: Compared to HC, patients clearly evinced a blunted HR response and displayed an attenuated PNS reactivity, as indicated by a less pronounced decline in RMSSD and HF-HRV (see Figures 4, 5). Relative to the control group, patients also demonstrated an attenuated SNS reactivity to stress, as indexed by a smaller increase in LF-HRV (Figure 6). Overall, patients and controls showed a similar general HRV reactivity as indicated by LF/HF-ratio and SDNN. Both groups presented sympathetic dominance during stress, with a slightly weaker SNS-reactivity in $\mathrm{P}_{\mathrm{AN}}$-but only at a descriptive level.

In general, the outcomes of the present study extended previous research and provided new data specific to $\mathrm{P}_{\mathrm{AN}}$ concerning their ANS response in the context of psychosocial 
TABLE 5a | HRV parameters in the resting condition.

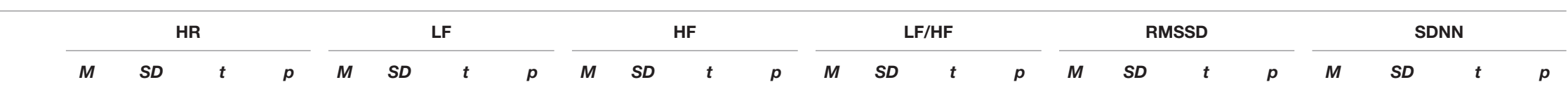

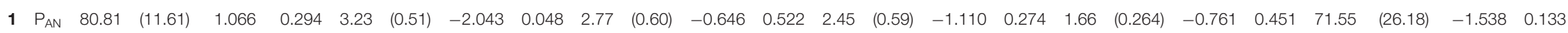

$\begin{array}{lllllllllllllll}\mathrm{HC} & 76.82 & (11.48) & & 3.57 & (0.50) & 2.90 & (0.65) & 2.66 & (0.55) & 1.73 & (0.31) & & 86.33 & (32.66)\end{array}$

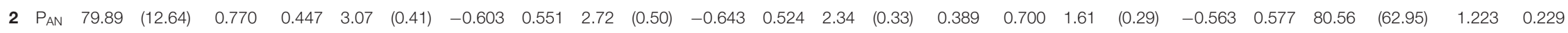

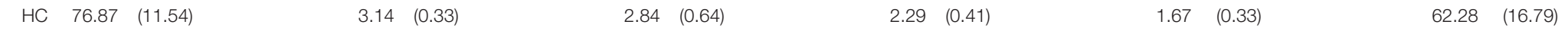

$\begin{array}{llllllllllllllllllllllllll}3 & \mathrm{P}_{\mathrm{AN}} & 78.18 & (12.33) & 1.007 & 0.321 & 3.06 & (0.48) & -0.727 & 0.472 & 2.78 & (0.63) & -0.532 & 0.598 & 2.27 & (0.33) & 0.032 & 0.975 & 1.61 & (0.29) & -0.567 & 0.575 & 81.06 & (65.21) & 1.001 & 0.323\end{array}$

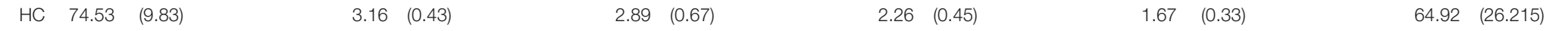

$\begin{array}{llllllllllllllllllllllllll}4 & \mathrm{P}_{\mathrm{AN}} & 78.58 & (11.66) & 1.177 & 0.247 & 2.90 & (0.44) & -1.152 & 0.257 & 2.67 & (0.60) & -1.073 & 0.290 & 2.23 & (0.33) & 0.399 & 0.692 & 1.60 & (0.29) & -0.864 & 0.393 & 55.55 & (24.44) & -0.423 & 0.675\end{array}$ $\begin{array}{llllllllllllll}\text { HC } & 74.53 & (9.41) & 3.06 & (0.42) & 2.88 & (0.60) & 2.18 & (0.40) & 1.68 & (0.32) & & 58.74 & (21.94)\end{array}$

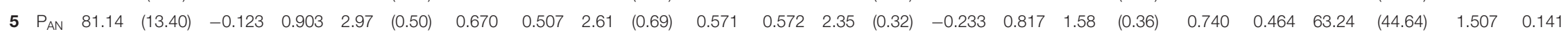

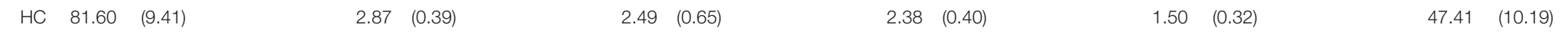

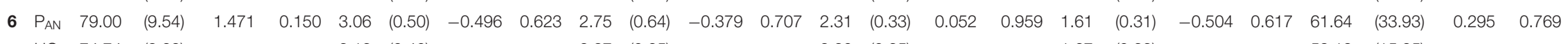

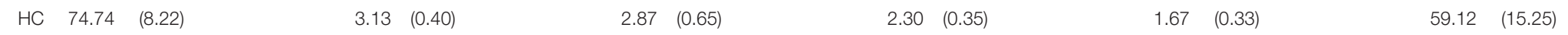

$\begin{array}{llllllllllllllllllllllllll}7 & P_{\text {AN }} & 78.43 & (10.28) & 0.811 & 0.423 & 3.05 & (0.55) & -0.034 & 0.973 & 2.81 & (0.68) & 0.147 & 0.884 & 2.23 & (0.31) & -0.730 & 0.470 & 1.64 & (0.33) & -0.632 & 0.531 & 64.75 & (36.47) & 0.983 & 0.332\end{array}$

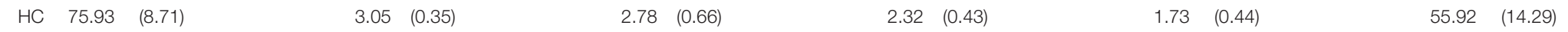

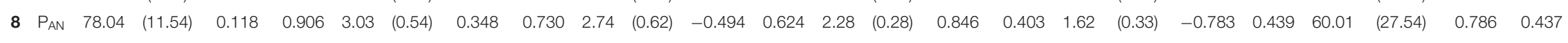
$\begin{array}{lllllllllllll}\mathrm{HC} & 77.64 & (8.87) & 2.97 & (0.42) & 2.84 & (0.68) & 2.18 & (0.47) & (13) & 1.73 & (0.47) & \end{array}$

Measurement timepoints =1 (Baseline), 2 (Rest), 3 (Rest), 4 (Rest), 5-8 (Recovery Phase). PAN, Participants with Anorexia Nervosa. HC, Healthy Controls; Log-transformed values (except HR and SDNN); HR, Heart Rate; LF, Low Frequency; HF, High Frequency; LF/HF-Ratio; RMSSD, Root Mean Square Standard Deviation; SDNN, Standard Deviation Normal to Normal. 
TABLE 5b | HRV parameters in the stress condition.

\begin{tabular}{|c|c|c|c|c|c|c|c|c|c|c|c|c|c|c|c|c|c|c|c|c|c|c|c|c|c|}
\hline \multirow[b]{2}{*}{ HR } & & \multicolumn{4}{|c|}{ HR } & \multicolumn{4}{|c|}{ LF } & \multicolumn{4}{|c|}{ HF } & \multicolumn{4}{|c|}{ LF/HF } & \multicolumn{4}{|c|}{ RMSSD } & \multicolumn{4}{|c|}{ SDNN } \\
\hline & & $M$ & $S D$ & $t$ & $p$ & $M$ & $S D$ & $t$ & $p$ & $M$ & $S D$ & $t$ & $p$ & $M$ & $S D$ & $t$ & $p$ & $M$ & $S D$ & $t$ & $p$ & $M$ & $S D$ & $t$ & $p$ \\
\hline \multirow[t]{2}{*}{1} & $P_{A N}$ & 78.87 & $(13.80)$ & 0.494 & 0.624 & 3.31 & $(0.60)$ & -1.884 & 0.068 & 2.79 & $(0.65)$ & -1.022 & 0.314 & 2.51 & $(0.59)$ & -0.748 & 0.459 & 1.66 & $(0.33)$ & -1.191 & 0.241 & 77.56 & $(34.56)$ & -1.576 & 0.120 \\
\hline & $\mathrm{HC}$ & 76.92 & (10.31) & & & 3.65 & $(0.50)$ & & & 2.99 & $(0.55)$ & & & 2.65 & (0.53) & & & 1.78 & (0.30) & & & 94.16 & (30.17) & & \\
\hline \multirow[t]{2}{*}{2} & $P_{A N}$ & 83.20 & (11.38) & 1.481 & 0.147 & 2.95 & $(0.40)$ & -2.359 & 0.024 & 2.57 & $(0.50)$ & -1.892 & 0.067 & 2.38 & $(0.26)$ & 0.533 & 0.597 & 1.57 & $(0.28)$ & -1.528 & 0.135 & 66.33 & (32.55) & -335 & 0.739 \\
\hline & $\mathrm{HC}$ & 78.33 & $(8.66)$ & & & 3.22 & $(0.29)$ & & & 2.89 & $(0.54)$ & & & 2.32 & $(0.34)$ & & & 1.72 & $(0.28)$ & & & 69.34 & $(21.74)$ & & \\
\hline \multirow[t]{2}{*}{3} & $P_{A N}$ & 89.15 & (13.07) & -2.802 & 0.008 & 2.98 & $(0.42)$ & 0.908 & 0.370 & 2.59 & $(0.61)$ & 1.180 & 0.246 & 2.39 & $(0.34)$ & -1.098 & 0.279 & 1.50 & $(0.31)$ & 1.339 & 0.189 & 64.51 & $(24.43)$ & 0.438 & 0.664 \\
\hline & $\mathrm{HC}$ & 104.04 & $(19.11)$ & & & 2.87 & $(0.35)$ & & & 2.35 & $(0.63)$ & & & 2.51 & $(0.35)$ & & & 1.37 & $(0.30)$ & & & 61.25 & $(21.35)$ & & \\
\hline \multirow[t]{2}{*}{4} & $P_{A N}$ & 88.14 & (13.88) & -2.633 & 0.012 & 2.98 & $(0.52)$ & 1.450 & 0.156 & 2.46 & $(0.63)$ & 1.291 & 0.205 & 2.521 & $(0.29)$ & -0.317 & 0.753 & 1.44 & $(0.29)$ & 1.770 & 0.085 & 58.05 & (27.57) & 1.662 & 0.106 \\
\hline & $\mathrm{HC}$ & 102.83 & $(19.97)$ & & & 2.75 & $(0.48)$ & & & 2.20 & $(0.62)$ & & & 2.54 & $(0.20)$ & & & 1.26 & $(0.33)$ & & & 45.11 & (19.79) & & \\
\hline \multirow[t]{2}{*}{5} & $P_{A N}$ & 81.86 & (15.03) & -0.492 & 0.625 & 2.97 & $(0.50)$ & 0.670 & 0.507 & 2.61 & $(0.69)$ & 0.571 & 0.572 & 2.35 & $(0.32)$ & -0.233 & 0.817 & 1.58 & $(0.36)$ & 0.740 & 0.464 & 70.64 & (67.98) & 1.331 & 0.198 \\
\hline & $\mathrm{HC}$ & 83.97 & (11.13) & & & 2.87 & $(0.39)$ & & & 2.49 & $(0.65)$ & & & 2.38 & $(0.40)$ & & & 1.50 & $(0.32)$ & & & 49.10 & (18.76) & & \\
\hline \multirow[t]{2}{*}{6} & $P_{A N}$ & 75.04 & (15.39) & -0.453 & 0.654 & 3.06 & $(0.50)$ & -0.496 & 0.623 & 2.75 & $(0.64)$ & -0.379 & 0.707 & 2.31 & $(0.33)$ & 0.052 & 0.959 & 1.61 & $(0.31)$ & -0.504 & 0.617 & 73.49 & $(47.50)$ & 0.624 & 0.538 \\
\hline & $\mathrm{HC}$ & 77.01 & $(10.94)$ & & & 3.13 & $(0.40)$ & & & 2.83 & $(0.65)$ & & & 2.30 & $(0.35)$ & & & 1.67 & $(0.33)$ & & & 66.00 & $(22.00)$ & & \\
\hline \multirow[t]{2}{*}{7} & $P_{A N}$ & 74.85 & (13.98) & 0.162 & 0.872 & 3.05 & $(0.55)$ & -0.034 & 0.973 & 2.81 & $(0.68)$ & 0.147 & 0.884 & 2.23 & $(0.31)$ & -0.730 & 0.470 & 1.64 & $(0.33)$ & -0.632 & 0.532 & 81.64 & $(78.10)$ & 1.189 & 0.243 \\
\hline & $\mathrm{HC}$ & 73.92 & (20.86) & & & 3.05 & $(0.35)$ & & & 2.78 & $(0.66)$ & & & 2.32 & $(0.43)$ & & & 1.73 & $(0.44)$ & & & 59.12 & (19.27) & & \\
\hline \multirow[t]{2}{*}{8} & $P_{A N}$ & 76.37 & (12.05) & 0.423 & 0.675 & 3.03 & $(0.54)$ & 0.348 & 0.730 & 2.74 & $(0.62)$ & -0.494 & 0.624 & 2.28 & $(0.28)$ & 0.846 & 0.403 & 1.62 & $(0.33)$ & -0.783 & 0.439 & 69.68 & $(44.72)$ & 1.189 & 0.228 \\
\hline & $\mathrm{HC}$ & 74.00 & (21.18) & & & 2.97 & $(0.42)$ & & & 2.84 & (0.68) & & & 2.18 & $(0.47)$ & & & 1.73 & $(0.47)$ & & & 55.64 & (19.47) & & \\
\hline
\end{tabular}

Measurement timepoints =1 (Baseline), 2 (Preparation), 3 (Before public speaking), 4 (After math task), 5-8 (Recovery Phase). PAN, Participants with Anorexia Nervosa; HC, Healthy Controls; Log-transformed values (except HR and SDNN). HR, Heart Rate; LF, Low Frequency; HF, High Frequency; LF/HF-Ratio. RMSSD, Root Mean Square Standard Deviation; SDNN, Standard Deviation Normal to Normal. 


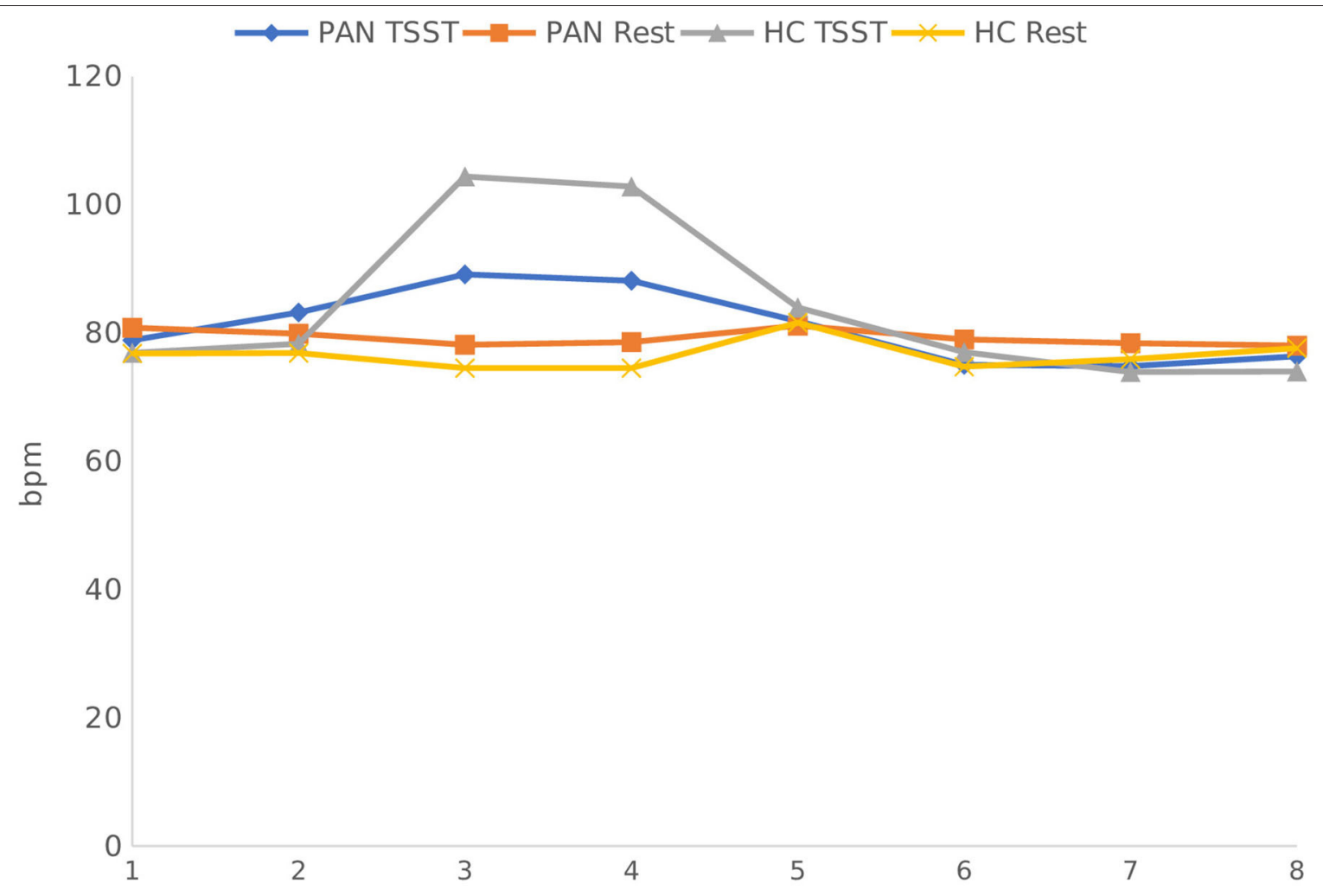

FIGURE 2 | Heart Rate Response in PAN and HC during stress and at rest. Measurement timepoints = 1 (Baseline), 2 (Preparation), 3 (Before public speaking), 4 (After math task), 5-8 (Recovery Phase). The measurements in the control condition were collected on equivalent timepoints.

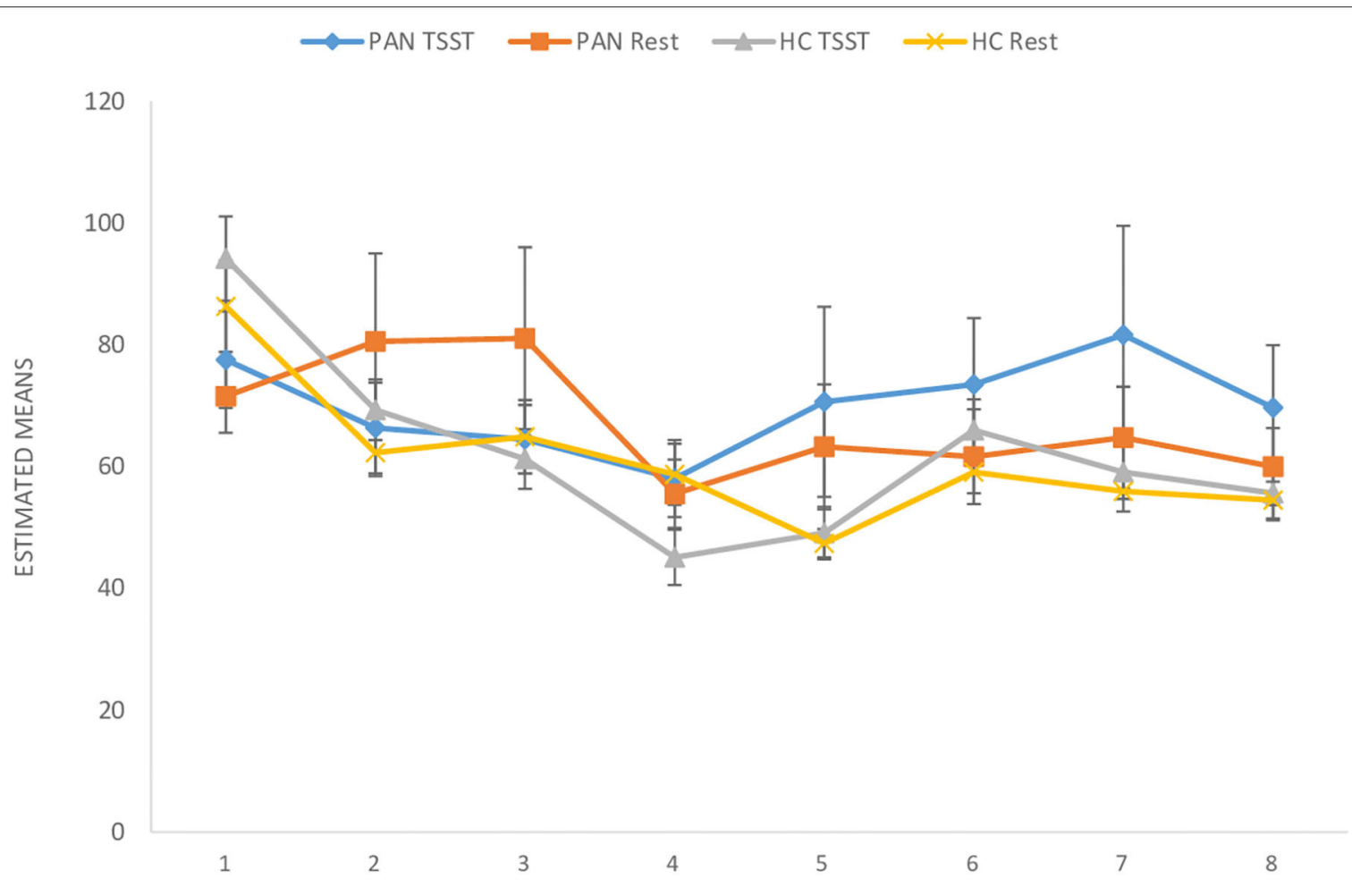

FIGURE 3 | SDNN (ms) in PAN and HC during stress and at rest. SDNN, Standard Deviation Normal to Normal. Measurement timepoints = 1 (Baseline), 2 (Preparation), 3 (Before public speaking), 4 (After math task), 5-8 (Recovery Phase). The measurements in the control condition were collected on equivalent timepoints. 

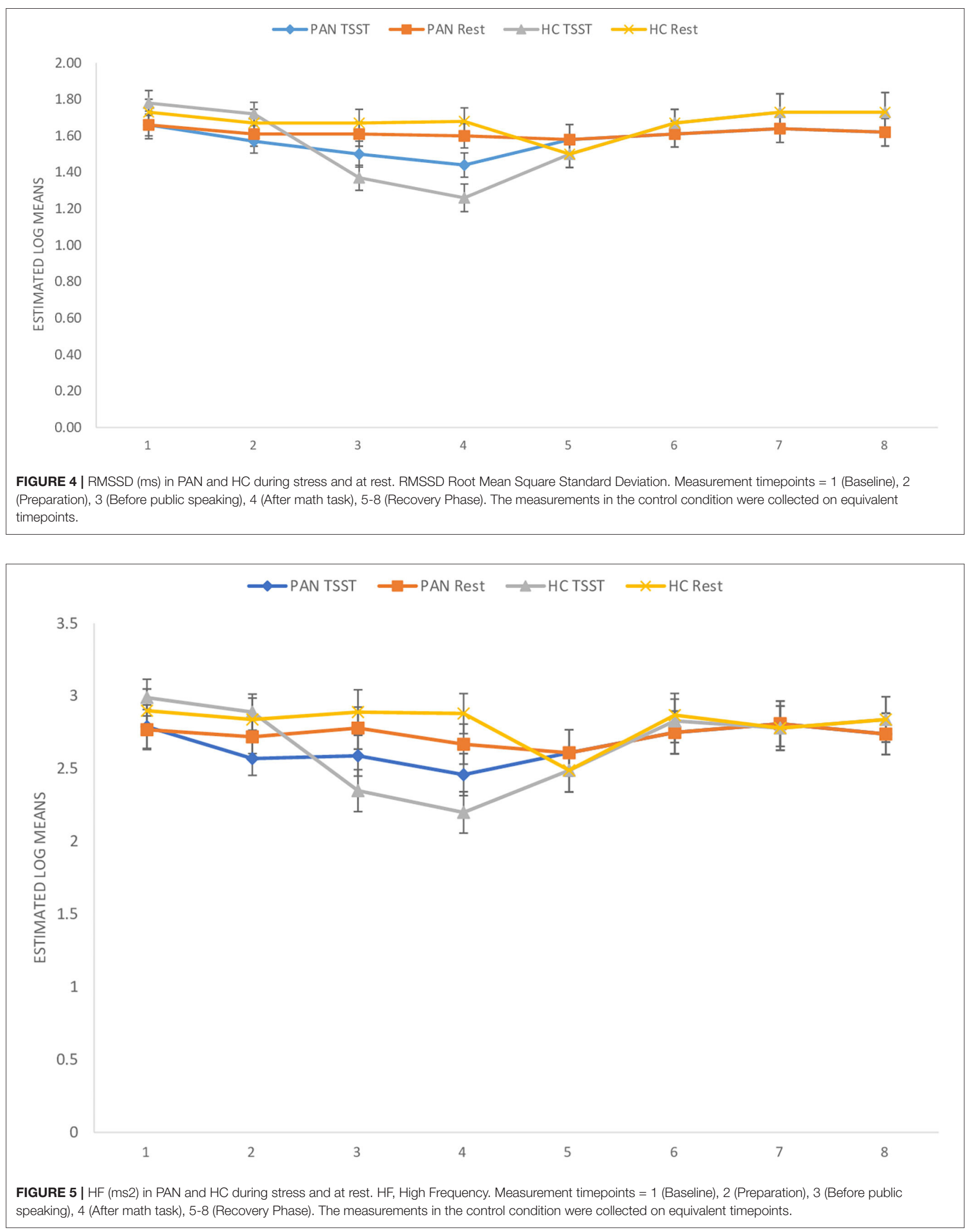


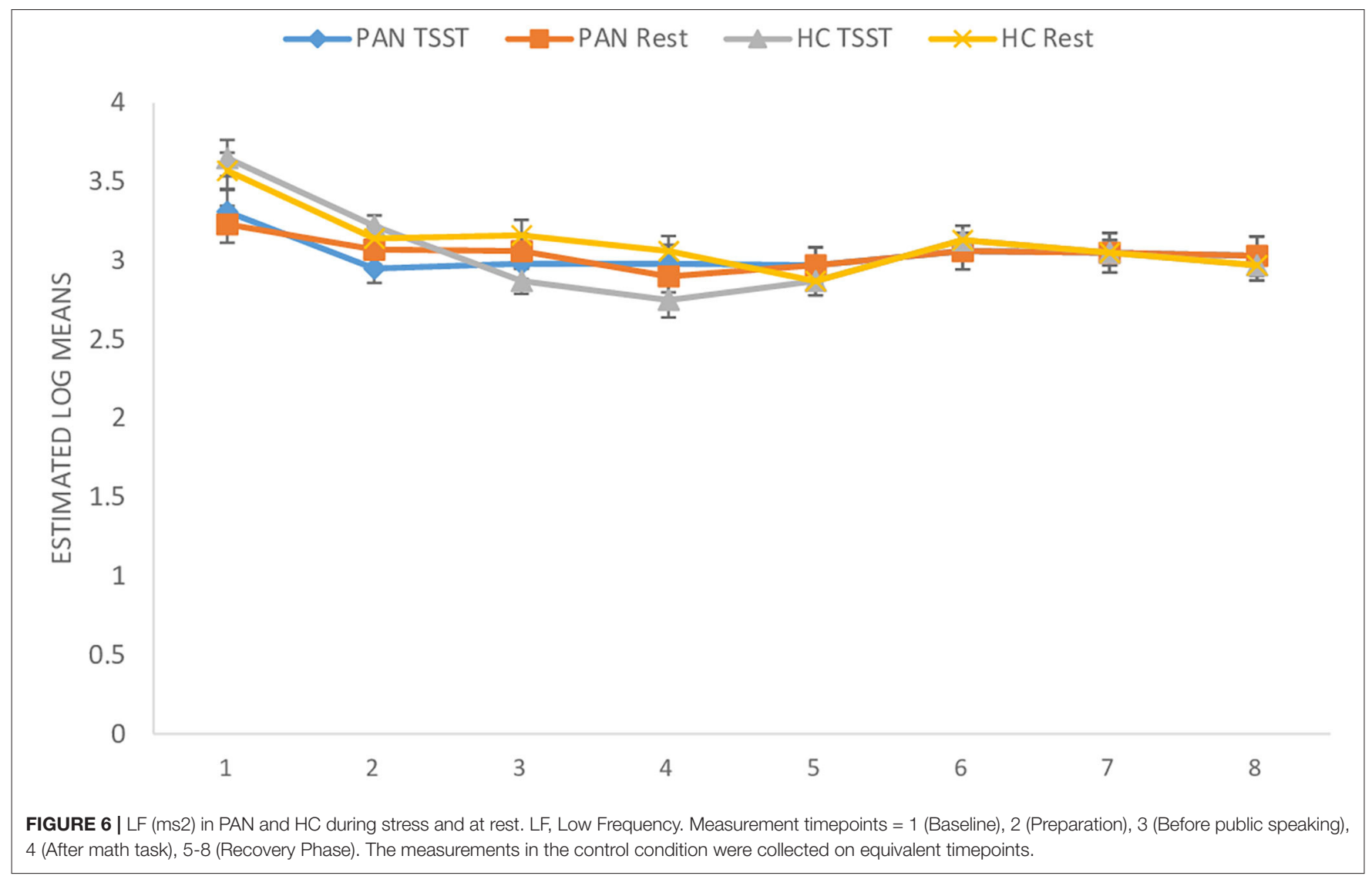

stress. $\left(\mathbf{H}_{1}\right)$ Contrary to our first hypothesis, our data indicated a similar tonic HR between $\mathrm{P}_{\mathrm{AN}}$ and $\mathrm{HC}$. This is in line with previous results reporting comparable baseline HRvalues between both groups (Zonnevylle-Bender et al., 2005; Monteleone et al., 2011; Het et al., 2020). Nevertheless, our findings contradicted those of Het et al. (2015), who found a significantly lower HR (baseline) in ED-patients than in healthy participants. The discrepancy between our findings and those of Het et al. (2015) can be explained by the quality of the patient sample. The patients in their study were recruited immediately after admission to a treatment clinic, implying an acute ED-phase, since they just started treatment. It is known that bradycardia is a common symptom in the acute phase of AN (Yoshida et al., 2006; Mazurak et al., 2011). In contrast, the participants in our sample were recruited after a stabilization phase during an inpatient treatment, showing a higher (mean) BMI than in the mentioned sample. $\left(\mathbf{H}_{2}\right)$ Further, we assumed parasympathetic hyperactivity and a decreased SNS activity in $\mathrm{P}_{\mathrm{AN}}$ at rest, compared to the HC. Our results confirmed the latter, expressing lower HRV-LF in $\mathrm{P}_{\mathrm{AN}}$, as previously described (Mazurak et al., 2011; Jacoangeli et al., 2013; Bomba et al., 2014). Nevertheless, parasympathetic hyperactivity in $\mathrm{P}_{\mathrm{AN}}$ could not be observed, since other HRV-parameters (HF, LF/HF, RMSSD, SDNN) were comparable between $\mathrm{P}_{\mathrm{AN}}$ and $\mathrm{HC}$. Hence, our second hypothesis only received partial support. This inconsistency between our result an those previously mentioned
(Mazurak et al., 2011; Jacoangeli et al., 2013; Bomba et al., 2014) are probably due to differences in the patient population. For instance, these studies included $\mathrm{P}_{\mathrm{AN}}$ with an average $\mathrm{BMI}$ between 12.9 and 17.7 , or $\mathrm{BMI} \leq 15$, implying emaciating. On the other hand, the $\mathrm{P}_{\mathrm{AN}}$ we evaluated were being treated and had recovered some weight. Therefore, it is plausible to assume that some irregularities in cardiovascular activity were restored, as previously shown in weight recovered patients (Miller et al., 2009; Het et al., 2020). Even so, abnormalities in $\mathrm{HR}$ and HRV reactivity were still observed in $\mathrm{P}_{\mathrm{AN}}$, as previously hypothesized $\left(\mathrm{H}_{3}, 4\right)$ : We expected a blunted $\mathrm{HR}$ response $\left(\mathbf{H}_{3}\right)$ and a low HRV reactivity $\left(\mathbf{H}_{4}\right)$ in $\mathrm{P}_{\mathrm{AN}}$ compared to HC. Our data confirmed both, replicating past evidence (e.g., Monteleone et al., 2011; Het et al., 2015, Monteleone et al., 2018; Het et al., 2020). Our last hypothesis $\left(\mathbf{H}_{5}\right)$ confirmed a reduced SNS reactivity in $\mathrm{P}_{\mathrm{AN}}$. However, a parasympathetic hyperreactivity could not be replicated. The former finding coincided with past studies reporting an attenuated sympathetic response to the TSST in patients (Monteleone et al., 2011; Het et al., 2015). Our latter finding of a parasympathetic inhibition in response to the TSST suggested an inadequate parasympathetic regulation, indicating difficulties in $\mathrm{P}_{\mathrm{AN}}$ to downregulate stress (Carney et al., 2005). This outcome fit the results of Rommel et al. (2015), who recorded a similar response pattern in a sample of $\mathrm{P}_{\mathrm{AN}}$ (SNS activity was not investigated), but contradicted the findings of Het et al. (2015) and Het et al. 


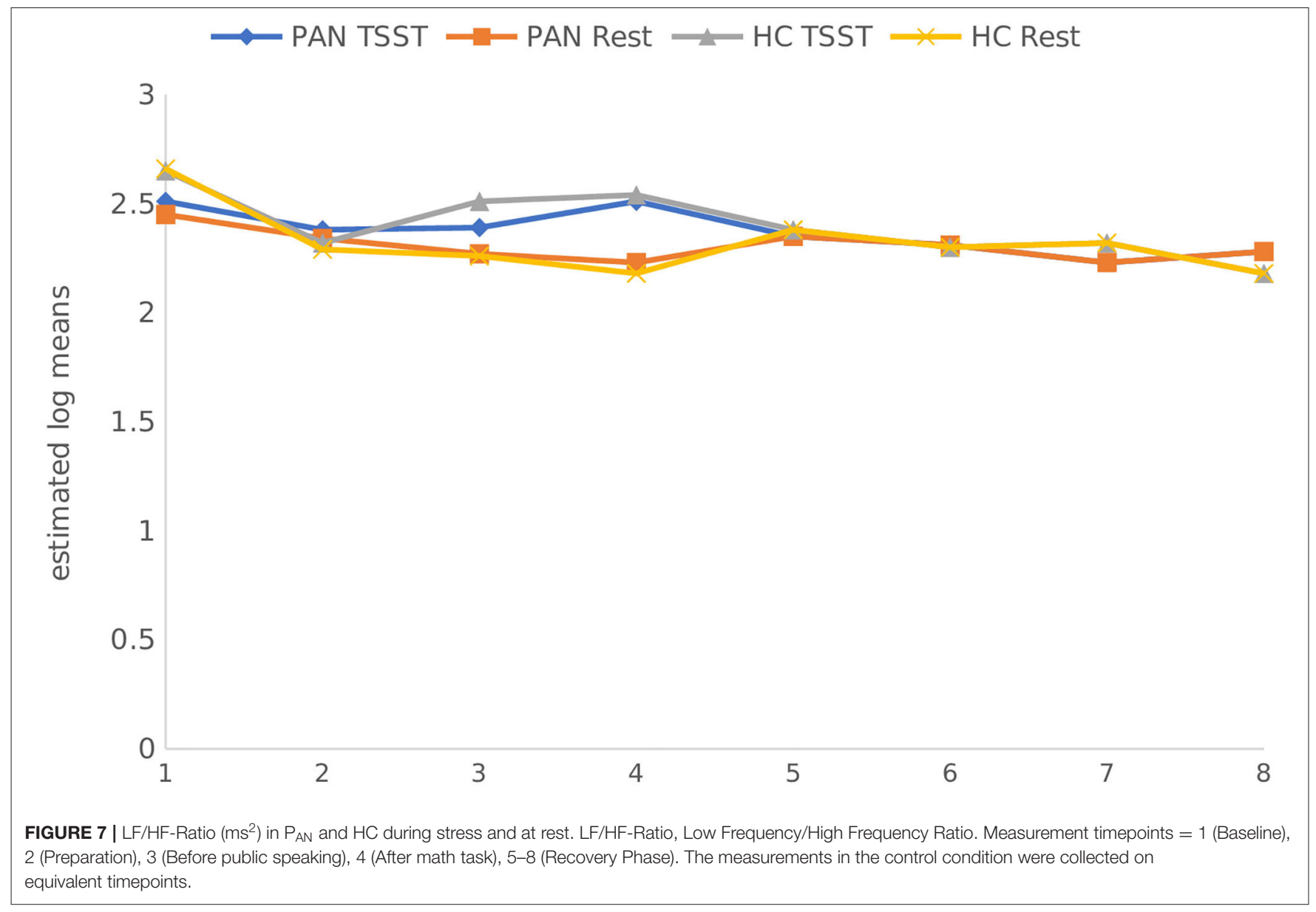

(2020). They rather observed parasympathetic dominance in their patient sample during early treatment (2015), and a normal PNS reactivity after treatment (2020). A plausible explanation might lie in the treatment status and sample composition, considering that our patient sample was in the middle of therapy and included only participants with $\mathrm{P}_{\mathrm{AN}}$, rather than an $\mathrm{ED}$ mixed group.

In short: compared to $\mathrm{HC}$, the patients in our study demonstrated hyporeactivity in both, SNS and PNS. This makes sense, since SNS is associated with dieting and chronic stress as indicated by pronounced values in TICS and marked EDsymptomatology (EDI) in our participants. On the other hand, PNS hyporeactivity is associated with depression (Jarrett et al., 2003), as indexed by elevated BDI-scores in our $P_{A N}$ sample. PNS hyperactivity is related to bradycardia and is mostly characteristic in the acute-phase of AN (as an adaptive mechanism; Roche et al., 2004; Yoshida et al., 2006) which was not observed in our sample. Consequently, it can be implied that ANS functionally was partially restored.

Ultimately, these findings provide strong evidence for a hyporesponsiveness of the ANS in $\mathrm{P}_{\mathrm{AN}}$. Overall, it was shown that abnormal ANS activity is partly reversed with weight recovery and treatment, but irregularities in reactivity persisted despite these changes. Specifically, (increased) stress appraisal and (low) weight significantly affected HRV reactivity (i.e., blunted response). In average, patients experienced stress as threatening and felt less skillful to cope with it. These outcomes are a major strength of the present study considering that HRV reactivity in the context of psychosocial stress has not been studied before in samples specific to $\mathrm{P}_{\mathrm{AN}}$. Many researchers who have conducted comparable experiments with ED-mixed samples pointed out the need of ED-specific findings, since there exist marked differences in emotional and physiological patterns (e.g., Peschel et al., 2016) that cannot be clearly identified if studied as a group. Further, our study offers an extensive analysis of the ANS reactivity in $\mathrm{P}_{\mathrm{AN}}$, which fosters understanding in the psychological and physiological mechanisms of their ANS response. At the same time, it provides input for potential treatment designs, e.g., HRV-Biofeedback training (Scolnick et al., 2014). Importantly, it suggests that ANS imbalances can manifest differently according to the stage of illness, treatment and weight status, as observed in different patient samples. A further strength of our research were the highly standardized context and laboratory setting: Homogenous samples of $\mathrm{HC}$ and patients due to our strict inclusion and exclusion criteria (which is pivotal for minimizing the influence of confounding variables). In addition, participants were perfectly age and gender matched. Moreover, we implemented a highly standardized stressor (TSST), which 
reliably activates the ANS. Notwithstanding, our study hosts some limitations. Regardless of the significant effects reported, an evident limitation is the small sample size in our study. Also, the generalizability of our findings is limited to female patients. Therefore, larger studies with more robust samples are needed to back up the results and to shed light on to the non-significant trends. A further limitation is that we were not able to collect data related to illness and treatment duration (e.g., number of days at the clinic before participation). Future research would benefit from including this data in future analyses. Thereupon, it remains to clarify whether ANS reactivity can be completely restored, not only after weight recovery, but specially after improving well-being and coping skills (e.g., stress appraisal). Additionally, further experiments may study the effects of HRV-biofeedback interventions on subjective stress appraisal and well-being. In conclusion, these findings suggested ANS hyporeactivity in $\mathrm{P}_{\mathrm{AN}}$, despite normalized basal activity. Specifically, it was revealed that ANS reactivity was most affected by heightened stress appraisal and low weight, rather than other psychological symptoms (e.g., general ED-symptomatology). Therefore, we supposed that besides weight recovery, improvement in stress appraisal would be beneficial. Consequently, it is recommended to help patients improve stress appraisal by developing and enhancing their coping and social skills. In addition, exercise sessions with biofeedback training might support cardiac health and HRVregulation. A combination of both may improve treatment outcomes and regulate stress reactivity.

\section{REFERENCES}

Arcelus, J., Mitchell, A. J., Wales, J., and Nielsen, S. (2011). Mortality rates in patients with anorexia nervosa and other eating disorders: a meta-analysis of 36 studies. Arch. Gen. Psychiatry 68, 724-731. doi: 10.1001/archgenpsychiatry.2011.74

Bär, K. J., Boettger, S., Wagner, G., Wilsdorf, C., Gerhard, U. J., Boettger, M. K., et al. (2006). Changes of pain perception, autonomic function, and endocrine parameters during treatment of anorectic adolescents. J. Am. Acad. Child Adol. Psychiatry 45, 1068-1076. doi: 10.1097/01.chi.0000227876.19 909.48

Beck, A. T., Steer, R. A., and Brown, G. K. (1996). Manual for the Beck Depression Inventory-II. San Antonio, TX: Psychological Corporation. 1, 82. doi: $10.1037 /$ t00742-000

Beck, A. T., Ward, C., Mendelson, M., Mock, J., and Erbaugh, J. (1961). Beck depression inventory (BDI). Arch. Gen. Psychiatr. 4, 561-571. doi: 10.1001/archpsyc.1961.01710120031004

Bomba, M., Corbetta, F., Gambera, A., Nicosia, F., Bonini, L., Neri, F., et al. (2014). Heart rate variability in adolescents with functional hypothalamic amenorrhea and anorexia nervosa. Psychiatry Res. 215, 406-409. doi: 10.1016/j.psychres.2013.11.012

Bosch, J. A., Veerman, E. C., de Geus, E. J., and Proctor, G. B. (2011). $\alpha$-Amylase as a reliable and convenient measure of sympathetic activity: don't start salivating just yet!. Psychoneuroendocrinology 36, 449-453. doi: 10.1016/j.psyneuen.2010.12.019

Caglar-Nazali, H. P., Corfield, F., Cardi, V., Ambwani, S., Leppanen, J., Olabintan, O., et al. (2014). A systematic review and meta-analysis of 'Systems for Social Processes' in eating disorders. Neurosci. Biobehav. Rev. 42, 55-92. doi: 10.1016/j.neubiorev.2013.12.002

Carney, R. M., Freedland, K. E., and Veith, R. C. (2005). Depression, the autonomic nervous system, and coronary heart disease. Psychosom. Med. 67, S29-S33. doi: 10.1097/01.psy.0000162254.61556.d5

\section{DATA AVAILABILITY STATEMENT}

The datasets presented in this article are available from the corresponding author, on reasonable request.

\section{ETHICS STATEMENT}

The studies involving human participants were reviewed and approved by Ethics Committee of the Medical faculty of the Technical University of Dresden, Germany (No\#EK25012013). The patients/participants provided their written informed consent to participate in this study.

\section{AUTHOR CONTRIBUTIONS}

KP and SW: conceptualization. BS and IS: methodology. KP and SW: software. HB, BS, and BH: validation. IS: formal analysis, writing-original draft preparation, visualization, and writingreview and editing. SP: investigation. SR: resources. $\mathrm{BH}$ : data curation. KP and HB: supervision. KP: project administration. All authors contributed to the article and approved the submitted version.

\section{FUNDING}

Open Access Funding by the Publication Fund of the TU Dresden.

Carpenter, R. (2016). A review of instruments on cognitive appraisal of stress. Arch. Psychiatr. Nurs. 30, 271-279. doi: 10.1016/j.apnu.2015.07.002

Cohen, M. A., Eliashberg, J., and Ho, T. H. (2000). An analysis of several new product performance metrics. Manuf. Serv. Operat. Manag. 2, 337-349. doi: $10.1287 / \mathrm{msom} \cdot 2.4 .337 .12341$

Dickerson, S. S., and Kemeny, M. E. (2004). Acute stressors and cortisol responses: a theoretical integration and synthesis of laboratory research. Psychol. Bull. 130:355. doi: 10.1037/0033-2909.130.3.355

Dinkel, A., Berth, H., Exner, C., Rief, W., and Balck, F. (2005). Deutsche adaptation der restraint scale zur erfassung gezügelten essverhaltens. Diagnostica 51, 67-74. doi: 10.1026/0012-1924.51.2.67

DSM-5 American Psychiatric Association (2013). Diagnostic and Statistical Manual of Mental Disorders. Arlington: American Psychiatric Publishing doi: 10.1176/appi.books.9780890425596

First, M. B., Gibbon, M., Spitzer, R. L., Benjamin, L. S., and Williams, J. B. (1997). Structured Clinical Interview for DSM-IV® Axis II Personality Disorders SCID-II. Washington, DC: American Psychiatric Pub.

Flint, A., Raben, A., Blundell, J. E., and Astrup, A. (2000). Reproducibility, power and validity of visual analogue scales in assessment of appetite sensations in single test meal studies. Int. J. Obes. 24, 38-48. doi: 10.1038/sj.ijo.0801083

Force, T. (1996). Standards of measurement, physiological interpretation and clinical use. Task force of the European Society of Cardiology and the North American Society of Pacing and Electrophysiology. Circulation. 93, 1043-1065.

Franke, G. H., and Derogatis, L. R. (2002). Symptom-Checkliste von LR Derogatis: SCL-90-R; deutsche Version. Göttingen: Beltz Test.

Gaab, J., Rohleder, N., Nater, U. M., and Ehlert, U. (2005). Psychological determinants of the cortisol stress response: the role of anticipatory cognitive appraisal. Psychoneuroendocrinology 30, 599-610. doi: 10.1016/j.psyneuen.2005.02.001

Garner, D. M., Olmstead, M. P., and Polivy, J. (1983). Development and validation of a multidimensional eating disorder inventory for anorexia nervosa and bulimia. Int Eating 
Disord. 2, 15-34. doi: 10.1002/1098-108X(198321)2:2\&lt;15::AIDEAT2260020203\&gt;3.0.CO;2-6

Gibson, D., Watters, A., Cost, J., Mascolo, M., and Mehler, P. S. (2020). Extreme anorexia nervosa: medical findings, outcomes, and inferences from a retrospective cohort. J. Eating Disord. 8, 1-10. doi: 10.1186/s40337-020-00303-6

Giovinazzo, S., Sukkar, S. G., Rosa, G. M., Zappi, A., Bezante, G. P., Balbi, M., et al. (2019). Anorexia nervosa and heart disease: a systematic review. Eat. Weight Disorders-Studies Anorexia, Bulimia Obes. 24, 199-207. doi: 10.1007/s40519-018-0567-1

Goldstein, D. S., Bentho, O., Park, M. Y., and Sharabi, Y. (2011). Low-frequency power of heart rate variability is not a measure of cardiac sympathetic tone but may be a measure of modulation of cardiac autonomic outflows by baroreflexes. Exp. Physiol. 96, 1255-1261. doi: 10.1113/expphysiol.2010.056259

Harbottle, E. J., Birmingham, C. L., and Sayani, F. (2008). Anorexia nervosa: a survival analysis. Eat. Weight Disorders. 13:e32-4.

Hautzinger, M., Bailer, M., Worall, H., and Keller, F. (1994). Beck-depressionsinventar (BDI). Bern: Huber.

Het, S., Vocks, S., Wolf, J. M., Hammelstein, P., Herpertz, S., and Wolf, O. T. (2015). Blunted neuroendocrine stress reactivity in young women with eating disorders. J. Psychosom. Res. 78, 260-267. doi: 10.1016/j.jpsychores.2014.11.001

Het, S., Vocks, S., Wolf, J. M., Herpertz, S., and Wolf, O. T. (2020). Treatmentresistant blunted HPA activity, but reversible cardiovascular stress reactivity in young women with eating disorders. Frontiers in Psychiatry. 11, 726. doi: 10.3389/fpsyt.2020.00726

Jacoangeli, F., Mezzasalma, F., Canto, G., Colica, C., De Lorenzo, A., and Iellamo, F. (2013). Baroreflex sensitivity and heart rate variability are enhanced in patients with anorexia nervosa. Int. J. Cardiol. 162:263-264. doi: 10.1016/j.ijcard.2012.10.073

Jarrett, M. E., Burr, R. L., Cain, K. C., Hertig, V., Weisman, P., and Heitkemper, M. M. (2003). Anxiety and depression are related to autonomic nervous system function in women with irritable bowel syndrome. Dig. Dis. Sci. 48, 386-394.

Jenkins, P. E., Hoste, R. R., Meyer, C., and Blissett, J. M. (2011). Eating disorders and quality of life: a review of the literature. Clin. Psychol. Rev. 31, 113-121. doi: 10.1016/j.cpr.2010.08.003

Kappel, V., Thiel, A., Holzhausen, M., Jaite, C., Schneider, N., Pfeiffer, E., et al. (2012). Eating disorder inventory-2 (EDI-2). Diagnostica. 58, 127-144. doi: 10.1026/0012-1924/a000069

Katzman, D. K. (2005). Medical complications in adolescents with anorexia nervosa: a review of the literature. Int. J. Eat. Disord. 37, S52-S59. doi: 10.1002/eat.20118

Kemper, K. J., Hamilton, C., and Atkinson, M. (2007). Heart rate variability: impact of differences in outlier identification and management strategies on common measures in three clinical populations. Pediatric Res. 62, 337-342.

Keshaviah, A., Edkins, K., Hastings, E. R., Krishna, M., Franko, D. L., Herzog, D. B., et al. (2014). Re-examining premature mortality in anorexia nervosa: a meta-analysis redux. Compr. Psychiatry 55, 1773-1784. doi: 10.1016/j.comppsych.2014.07.017

Kirschbaum, C., Pirke, K. M., and Hellhammer, D. H. (1993). The 'Trier Social Stress Test'-a tool for investigating psychobiological stress responses in a laboratory setting. Neuropsychobiology 28, 76-81. doi: 10.1159/000119004

Klaghofer, R., and Brähler, E. (2001). Konstruktion und Teststatistische Prüfung einer Kurzform der SCL-90-R. Zeitschrift für Klinische Psychologie, Psychiatrie und Psychotherapie. 49, 115-124.

Kudielka, B. M., Hellhammer, D. H., Kirschbaum, C., Harmon-Jones, E., and Winkielman, P. (2007). Ten years of research with the Trier Social Stress Test-revisited. Soc. Neurosci. 56:83. doi: 10.1016/B978-012373947-6.00681-4

Kühner, C., Bürger, C., Keller, F., and Hautzinger, M. (2007). Reliabilität und validität des revidierten beck-depressionsinventars (BDI-II). Nervenarzt 78, 651-656. doi: 10.1007/s00115-006-2098-7

Lachish, M., Stein, D., Kaplan, Z., Matar, M., Faigin, M., Korsunski, I., et al. (2009). Irreversibility of cardiac autonomic dysfunction in female adolescents diagnosed with anorexia nervosa after short-and long-term weight gain. World J. Biol. Psychiatry 10, 503-511. doi: 10.1080/15622970902980770

Lesage, F. X., Berjot, S., and Deschamps, F. (2012). Clinical stress assessment using a visual analogue scale. Occup. Med. (Chic. Ill). 62, 600-605. doi: 10.1093/occmed/kqs140

Lischke, A., Jacksteit, R., Mau-Moeller, A., Pahnke, R., Hamm, A. O., and Weippert, M. (2018). Heart rate variability is associated with psychosocial stress in distinct social domains. J. Psychosom. Res. 106, 56-61. doi: 10.1016/j.jpsychores.2018.01.005

Marques, A. H., Silverman, M. N., and Sternberg, E. M. (2010). Evaluation of stress systems by applying noninvasive methodologies: measurements of neuroimmune biomarkers in the sweat, heart rate variability and salivary cortisol. Neuroimmunomodulation 17, 205-208. doi: $10.1159 / 000258725$

Mazurak, N., Enck, P., Muth, E., Teufel, M., and Zipfel, S. (2011). Heart rate variability as a measure of cardiac autonomic function in anorexia nervosa: a review of the literature. Europ. Eat. Disord. Rev. 19, 87-99. doi: 10.1002/erv.1081

Miller, S. P., Erickson, S. J., Branom, C., and Steiner, H. (2009). Habitual response to stress in recovering adolescent anorexic patients. Child Psychiatry Hum. Dev. 40, 43-54. doi: 10.1007/s10578-008-0112-y

Mohammadi, A., Emamgoli, A., Shirinkalam, M., Meftahi, G. H., Yagoobi, K., and Hatef, B. (2019). The persistent effect of acute psychosocial stress on heart rate variability. Egypt. Heart J. 71, 1-9. doi: 10.1186/s43044-019-0009-z

Monteleone, A. M., Treasure, J., Kan, C., and Cardi, V. (2018). Reactivity to interpersonal stress in patients with eating disorders: a systematic review and meta-analysis of studies using an experimental paradigm. Neurosci. Biobehav. Rev. 87, 133-150. doi: 10.1016/j.neubiorev.2018.02.002

Monteleone, P., Scognamiglio, P., Canestrelli, B., Serino, I., Monteleone, A. M., and Maj, M. (2011). Asymmetry of salivary cortisol and [alpha]-amylase responses to psychosocial stress in anorexia nervosa but not in bulimia nervosa. Psychol. Med. 41:1963. doi: 10.1017/S0033291711000092

Murialdo, G., Casu, M., Falchero, M., Brugnolo, A., Patrone, V., Cerro, P. F., et al. (2007). Alterations in the autonomic control of heart rate variability in patients with anorexia or bulimia nervosa: correlations between sympathovagal activity, clinical features, and leptin levels. J. Endocrinol. Invest. 30, 356-362. doi: 10.1007/BF03346310

Murray, S. B., Quintana, D. S., Loeb, K. L., Griffiths, S., and Le Grange, D. (2019). Treatment outcomes for anorexia nervosa: a systematic review and meta-analysis of randomized controlled trials. Psychol. Med. 49, 535-544. doi: 10.1017/S0033291718002088

Peschel, S. K., Feeling, N. R., Vögele, C., Kaess, M., Thayer, J. F., and Koenig, J. (2016). A systematic review on heart rate variability in Bulimia Nervosa. Neurosci. Biobehav. Rev. 63, 78-97. doi: 10.1016/j.neubiorev.2016.01.012

Petrowski, K., Kliem, S., Albani, C., Hinz, A., and Brähler, E. (2019a). Norm values and psychometric properties of the short version of the Trier Inventory for Chronic Stress (TICS) in a representative German sample. PLoS ONE 14:e0222277. doi: 10.1371/journal.pone.0222277

Petrowski, K., Kliem, S., Sadler, M., Meuret, A. E., Ritz, T., and Brähler, E. (2018). Factor structure and psychometric properties of the english version of the trier inventory for chronic stress (TICS-E). BMC Med. Res. Methodol. 18:18. doi: 10.1186/s12874-018-0471-4

Petrowski, K., Paul, S., Albani, C., and Brähler, E. (2012). Factor structure and psychometric properties of the Trier Inventory for Chronic Stress (TICS) in a representative German sample. BMC Med. Res. Methodol. 12:42. doi: 10.1186/1471-2288-12-42

Petrowski, K., Schmalbach, B., Kliem, S., Hinz, A., and Brähler, E. (2019b). Symptom-Checklist-K-9: Norm values and factorial structure in a representative German sample. PLoS ONE. 14:e0213490. doi: 10.1371/journal.pone.0213490

Platisa, M. M., Nestorovic, Z., Damjanovic, S., and Gal, V. (2006). Linear and non-linear heart rate variability measures in chronic and acute phase of anorexia nervosa. Clin. Physiol. Funct. Imaging 26, 54-60. doi: 10.1111/j.1475-097X.2005.00653.x

Portilla, M. G. (2011). Bradycardia: an important physical finding in anorexia nervosa. J. Ark. Med. Soc. 107, 206-208.

Prinz, U., Nutzinger, D. O., Schulz, H., Petermann, F., Braukhaus, C., and Andreas, S. (2013). Comparative psychometric analyses of the SCL-90-R and its short versions in patients with affective disorders. BMC Psychiatry 13:104. doi: 10.1186/1471-244X-13-104

Pruessner, J. C., Kirschbaum, C., Meinlschmid, G., and Hellhammer, D. H. (2003). Two formulas for computation of the area under the curve represent measures of total hormone concentration versus time-dependent change. Psychoneuroendocrinology 28, 916-931. doi: 10.1016/S0306-4530(02) 00108-7 
Roche, F., Barthélémy, J. C., Garet, M., Costes, F., Pichot, V., Duverney, D., et al. (2004). Chronotropic incompetence to exercise separates low body weight from established anorexia nervosa. Clin. Physiol. Funct. Imaging 24, 270-275. doi: 10.1111/j.1475-097X.2004.00561.x

Rommel, D., Nandrino, J. L., De Jonckheere, J., Swierczek, M., Dodin, V., and Logier, R. (2015). Maintenance of parasympathetic inhibition following emotional induction in patients with restrictive type anorexia nervosa. Psychiatry Res. 225, 651-657. doi: 10.1016/j.psychres.2014.11.030

Sachs, K. V., Harnke, B., Mehler, P. S., and Krantz, M. J. (2016). Cardiovascular complications of anorexia nervosa: a systematic review. Int. J. Eat. Disord. 49, 238-248. doi: 10.1002/eat.22481

Schulz, P., Schlotz, W., and Becker, P. (2004). Trierer Inventar zum Chronischen Stress (TICS) [Trier Inventory for Chronic Stress (TICS)]. Gottingen. Hogrefe 61.

Scolnick, B., Mostofsky, D. I., and Keane, R. J. (2014). Pilot study employing heart rate variability biofeedback training to decrease anxiety in patients with eating disorders. J. Eat. Disord. 2:17. doi: 10.1186/2050-2974-2-17

Seidel, M., King, J., Ritschel, F., Boehm, I., Geisler, D., Bernardoni, F. ..., et al. (2018). The real-life costs of emotion regulation in Anorexia nervosa: a combined ecological momentary assessment and fMRI study. Transl. Psychiatry 8:28. doi: 10.1038/s41398-017-0004-7

Sereda, Y., and Dembitskyi, S. (2016). Validity assessment of the symptom checklist SCL-90-R and shortened versions for the general population in Ukraine. BMC Psychiatry 16:1. doi: 10.1186/s12888-016-1014-3

Shaffer, F., and Ginsberg, J. P. (2017). An overview of heart rate variability metrics and norms. Front. Public Health. 5:258. doi: 10.3389/fpubh.2017.00258

Stein, P. K., and Kleiger, R. E. (1999). Insights from the study of heart rate variability. Annu. Rev. Med. 50, 249-261. doi: 10.1146/annurev.med.50.1.249

Thayer, J. F., Yamamoto, S. S., and Brosschot, J. F. (2010). The relationship of autonomic imbalance, heart rate variability and cardiovascular disease risk factors. Int. J. Cardiol. 141, 122-131. doi: 10.1016/j.ijcard.2009.09.543

Thiel, A., and Paul, T. (1988). Entwicklung einer deutschsprachigen Version des Eating-Disorder-Inventory (EDI). Zeitschrift für Differentielle und Diagnostische Psychologie. 9, 267-278.

Tomba, E., Tecuta, L., Schumann, R., and Ballardini, D. (2017). Does psychological well-being change following treatment? An exploratory study on outpatients with eating disorders. Compr. Psychiatry 74, 61-69. doi: 10.1016/j.comppsych.2017.01.001

Vigo, D. E., Castro, M. N., Dörpinghaus, A., Weidema, H., Cardinali, D. P., Siri, L. N., et al. (2008). Nonlinear analysis of heart rate variability in patients with eating disorders. World J. Biol. Psychiatry.9, 183-189. doi: $10.1080 / 15622970701261604$
Vocks, S., Wächter, A., Wucherer, M., and Kosfelder, J. (2008). Look at yourself: Can body image therapy affect the cognitive and emotional response to seeing oneself in the mirror in eating disorders?. Europ. Eat. Disord. Rev. 16, 147-154. doi: 10.1002 /erv. 825

Watson, H. J., and Bulik, C. M. (2013). Update on the treatment of anorexia nervosa: review of clinical trials, practice guidelines and emerging interventions. Psychol. Med. 43:2477. doi: 10.1017/S0033291712002620

Wierenga, C. E., Lavender, J. M., and Hays, C. C. (2018). The potential of calibrated fMRI in the understanding of stress in eating disorders. Neurobiol. Stress. 9, 64-73. doi: 10.1016/j.ynstr.2018.08.006

Wittchen, H. U., Wunderlich, U., Gruschwitz, S., and Zaudig, M. (1997). SKID-I: Strukturiertes klinisches interview für DSM-IV, Achse I: psychische störungen.

Yoshida, N., Kazuhiro, Y., Hiroaki, K., Tadashi, S., and Tomifusa, K., (2006). Changes in heart rate with refeeding in anorexia nervosa: a pilot study. J. Psych. Res. 61,571-575. doi: 10.1016/j.jpsychores.2006.02.009

Young, H., and Benton, D. (2015). We should be using nonlinear indices when relating heart-rate dynamics to cognition and mood. Sci. Rep., 5, 1-16.

Young, H. A., and Benton, D. (2018). Heart-rate variability: a biomarker to study the influence of nutrition on physiological and psychological health?. Behav. Pharmacol. 29:140. doi: 10.1097/FBP.0000000000000383

Zaunseder, S., Fischer, W. J., Poll, R., and Rabenau, M. (2008). "Wavelet-based real-time ECG processing for a wearable monitoring system," in Proceedings of the First International Conference on Bio-inspired Systems and Signal Processing (Dresden), 255-260. doi: 10.5220/0001065002550260

Zonnevylle-Bender, M. J., Van Goozen, S. H., Cohen-Kettenis, P. T., Jansen, L. M., Van Elburg, A., and Van Engeland, H. (2005). Adolescent anorexia nervosa patients have a discrepancy between neurophysiological responses and selfreported emotional arousal to psychosocial stress. Psychiatry Res. 135, 45-52. doi: 10.1016/j.psychres.2004.11.006

Conflict of Interest: The authors declare that the research was conducted in the absence of any commercial or financial relationships that could be construed as a potential conflict of interest.

Copyright (C) 2021 Schmalbach, Herhaus, Pässler, Runst, Berth, Wolff, Schmalbach and Petrowski. This is an open-access article distributed under the terms of the Creative Commons Attribution License (CC BY). The use, distribution or reproduction in other forums is permitted, provided the original author(s) and the copyright owner(s) are credited and that the original publication in this journal is cited, in accordance with accepted academic practice. No use, distribution or reproduction is permitted which does not comply with these terms. 